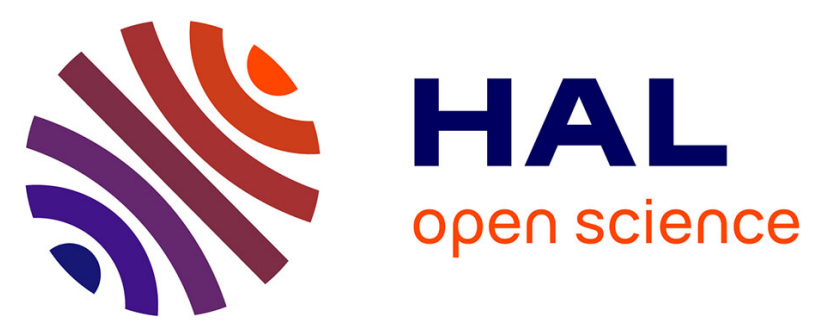

\title{
A 1 year sea surface heat budget in the northeastern Atlantic basin during the POMME experiment: 1. Flux estimates.
}

Guy Caniaux, Aurore Brut, Denis Bourras, Hervé Giordani, A. Paci, Louis Prieur, Gilles Reverdin

\section{To cite this version:}

Guy Caniaux, Aurore Brut, Denis Bourras, Hervé Giordani, A. Paci, et al.. A 1 year sea surface heat budget in the northeastern Atlantic basin during the POMME experiment: 1. Flux estimates.. Journal of Geophysical Research. Oceans, 2005, 110 (C7), pp.C07S02. 10.1029/2004JC002596 . hal00145753

\section{HAL Id: hal-00145753 \\ https://hal.science/hal-00145753}

Submitted on 30 Jan 2016

HAL is a multi-disciplinary open access archive for the deposit and dissemination of scientific research documents, whether they are published or not. The documents may come from teaching and research institutions in France or abroad, or from public or private research centers.
L'archive ouverte pluridisciplinaire HAL, est destinée au dépôt et à la diffusion de documents scientifiques de niveau recherche, publiés ou non, émanant des établissements d'enseignement et de recherche français ou étrangers, des laboratoires publics ou privés. 


\title{
A 1 year sea surface heat budget in the northeastern Atlantic basin during the POMME experiment:
}

\section{Flux estimates}

\author{
G. Caniaux, ${ }^{1}$ A. Brut, ${ }^{1}$ D. Bourras, ${ }^{2}$ H. Giordani, ${ }^{1}$ A. Paci, ${ }^{1}$ L. Prieur, ${ }^{3}$ and G. Reverdin ${ }^{4}$ \\ Received 15 July 2004; revised 10 February 2005; accepted 3 March 2005; published 2 July 2005.
}

[1] The aim of the Programme Océan Multidisciplinaire Méso Echelle (POMME) was to study the formation and subduction of $11^{\circ}-13^{\circ} \mathrm{C}$ waters in the northeast Atlantic $\left(21^{\circ}-15^{\circ} \mathrm{W}\right.$ and $\left.38^{\circ}-45^{\circ} \mathrm{N}\right)$. An extensive oceanic and atmospheric data set was collected over 1 year during the period September 2000-October 2001. Owing to the importance of energy and water exchanges between the top layers of the ocean and the atmosphere in the subduction process, a surface heat, freshwater, and momentum budget has been computed combining the use of satellite products, in situ data, and atmospheric model outputs. This data set has been compared and validated with observations collected from a moored buoy and an instrumented mast onboard a research vessel. Each component of the net heat, freshwater, and momentum flux has been individually evaluated, and turbulent fluxes were computed with a state-of-the-art bulk flux algorithm deduced from turbulence measurements made during the experiment. We have adopted a $5 \mathrm{~km}$ grid spacing to take into account the oceanic mesoscale variability. The annual domainaveraged heat flux is positive $\left(+33 \mathrm{~W} \mathrm{~m}^{-2}\right)$, indicating a heating of the ocean, whereas model estimates (European Centre for Medium-Range Weather Forecasts (ECMWF) and the French operational weather forecast model, ARPEGE) indicate a negative (cooling) budget ( $-9 \mathrm{~W} \mathrm{~m}^{-2}$ and $-25 \mathrm{~W} \mathrm{~m}^{-2}$, respectively). Sensitivity tests of the parameterization used and the sea surface temperature used place the accuracy of the budget to about $10 \mathrm{~W} \mathrm{~m}^{-2}$. The freshwater budget is negative, implying a freshening of the ocean, as in the ECMWF model. Our assessment proves that sea surface temperature patterns condition the mesoscale patterns of the heat budget, a feature that is not reproduced by models.

Citation: Caniaux, G., A. Brut, D. Bourras, H. Giordani, A. Paci, L. Prieur, and G. Reverdin (2005), A 1 year sea surface heat budget in the northeastern Atlantic basin during the POMME experiment: 1. Flux estimates, J. Geophys. Res., 110, C07S02, doi:10.1029/2004JC002596.

\section{Introduction}

[2] Knowledge of air-sea exchanges (momentum, heat and freshwater) is of great importance in understanding the interactions between the ocean and the atmosphere at local and global scales. Surface fluxes are essential inputs of oceanic models for the top layers of the ocean because of their direct action in modifying sea surface temperature (SST), sea surface salinity (SSS) and the mixed layer depth.

[3] A good estimate of surface fluxes is necessary to quantify the rate at which mixed layer water is incorporated

\footnotetext{
${ }^{1}$ Centre National de Recherches Météorologiques, Toulouse, France. ${ }^{2}$ Centre d'Etude des Environnements Terrestre et Planétaires, Velisy, France.

${ }^{3}$ Laboratoire d'Océanographie de Villefranche-sur-mer, Villefranchesur-mer, France.

${ }^{4}$ Laboratoire d'Océanographie et du Climat: Expérimentation et Approche Numérique, Institut Pierre Simon Laplace, Paris, France.

Copyright 2005 by the American Geophysical Union. 0148-0227/05/2004JC002596
}

into the main thermocline after being in contact with the atmosphere during the winter season [Marshall et al., 1993; Qiu and Huang, 1995]. This point was one of the major scientific objectives of the Programme Océan Multidisciplinaire Méso Echelle (POMME) [Mémery et al., 2005], a program devoted to studying the subduction mechanisms of the northeast Atlantic and, more precisely, the role of mesoscale structures on the subduction of the $11^{\circ}-13^{\circ} \mathrm{C}$ water off the Iberian peninsula [Paillet and Arhan, 1996].

[4] The experimental domain of POMME was centered near $42^{\circ} \mathrm{N}$ and $18^{\circ} \mathrm{W}$ (Figure 1), north of the Subduction Experiment conducted between June 1991 and June 1993 [Moyer and Weller, 1997]. It covered an area of nearly $500 \mathrm{~km}$ in longitude and $750 \mathrm{~km}$ in latitude, in a region where the deepest winter mixed layer reaches hundreds of meters, generally being deeper in the north than in the south of the area. Moreover, weak subsurface currents are thought to export subducted waters southward [Woods and Barkmann, 1986]. This region is known as the "zero flux region" with a negative annual buoyancy flux north and 


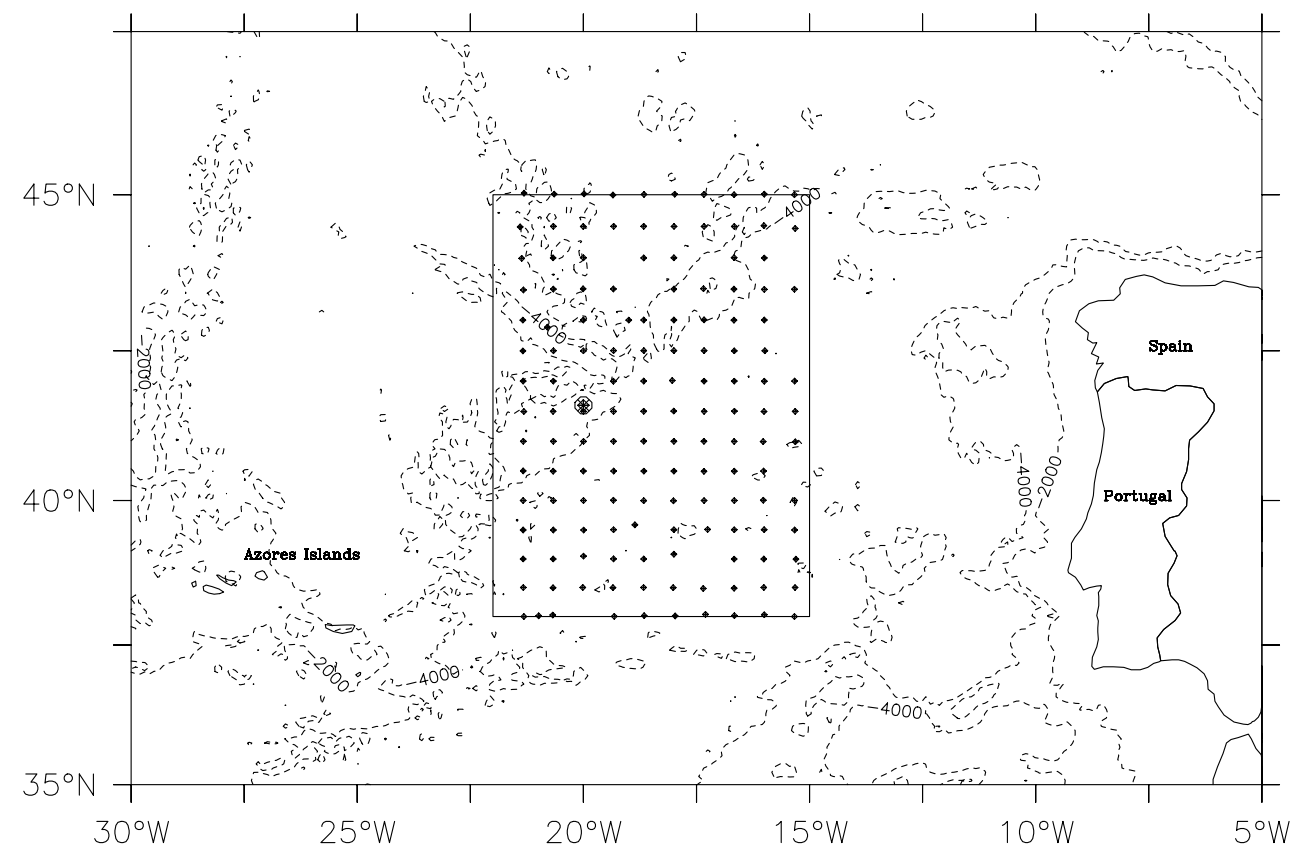

Figure 1. Map of the study area. The small dots in the Programme Océan Multidisciplinaire Méso Echelle (POMME) rectangle are the locations of conductivity-temperature-depth (CTD) casts performed during POMME1/Leg1; the large black dot indicates the position of the moored buoy. The bathymetry of the area is indicated in dashed lines at $-4000 \mathrm{~m}$ and $-2000 \mathrm{~m}$ depths.

positive fluxes south [Isemer and Hasse, 1985]. However, recent estimates by Weller et al. [2004] with regards to the large-scale context of subduction in the Northeast Atlantic strongly question these patterns, as they found that over the entire region the ocean gained more heat overall than indicated by the climatology.

[5] Four experiments at sea were carried out over 1 year: the first one (POMME0, hereafter P0) was carried out in September-October 2000, the second one (P1) in FebruaryMarch 2001 during the maximum of near surface convection; the third one in March-May 2001 (P2) during the spring bloom and the last one in August-September 2001 (P3). During these surveys (of nearly 250 days), systematic conductivity-temperature-depth (CTD)-expendable bathythermograph (XBT) casts, acoustic Doppler current profiler (ADCP), biological and chemical sampling, towed CTD Seasoars and surface sampling were carried out. Continuous measurements were recorded from surface drifters equipped with meteorological instruments, subsurface and profiling floats, as well as from moorings (current, temperature, sediment traps). One mooring was specifically devoted to air-sea interactions.

[6] One of the central requirements of POMME was to obtain reliable, gridded flux fields, including heat, freshwater and momentum fluxes, on a fine grid (in order to represent the oceanic mesoscale) and at a fairly high frequency (compatible with the evolution of upper layer features) over a 1 year period [McLaren and Williams, 2001]. The main motivation for this was to consequently be able to realistically simulate the POMME area with three-dimensional numerical models driven by realistic atmospheric forcing, to analyze the effect of mesoscale features on the subduction process and to simulate biological processes in the mixed layer.
[7] A first approach in achieving this objective is to use numerical weather prediction (NWP) model fluxes. In theory, gridded fluxes are available at all time steps of the model. Unfortunately, many studies indicate that NWP model fluxes are often biased [Eymard et al., 1999; Josey, 2001; Renfrew et al., 2002, and references therein] and that it is difficult to correct their errors [Bonekamp et al., 2002]. A second approach is to use satellite flux estimates; due to their fine spatial and temporal coverage, satellites can provide flux estimates at a fine resolution [Curry et al., 1999, 2004; Bourras et al., 2003]. However, a complete buoyancy budget requires calibrations which are not completely satisfactory, particularly for humidity [Schulz et al., 1993] and for precipitation retrieval [Sheu et al., 1996]. A third possibility is to use a synthesis approach as in the work of Caniaux and Planton [1998], which consists in selecting the best available products among different data sets and flux algorithms, to determine separately all the components of the surface budget.

[8] This last approach has been applied in this paper, i.e., we selected satellite radiative fluxes (longwave and shortwave), with specifically produced SST analyses, and computed turbulent fluxes from NWP basic observables (atmospheric pressure, air temperature and humidity, wind and precipitation) using an up-to-date bulk algorithm.

[9] Previous studies of flux comparison concerning either NWP models [Sun et al., 2003], or climatologies [Kubota et al., 2003], or both [Josey, 2001] suggest that the accuracy of fluxes strongly depends on different sources of errors. In order to minimize these errors, great care must be taken (1) to thoroughly validate the input data of the budget, as indicated by recent studies by Weller and Anderson [1996], Smith et al. [2001], and Sun et al. [2003]; (2) to pay attention to the spatial and temporal 
Table 1. Characteristics of the Sensors Onboard the Moored OSAS Buoy ${ }^{\mathrm{a}}$

\begin{tabular}{lccc}
\hline \multicolumn{1}{c}{ Parameter } & Sensor & Measurement & Accuracy \\
\hline Pressure, $\mathrm{hPa}$ & AIR SB2A & $800-1060$ & $0-150$ \\
Wind velocity, $\mathrm{kts}$ & VECTOR A100L2 & $0-360$ & \pm 0.5 \\
Wind direction, deg & VECTOR SRW1G-M & $-40+70$ & \pm 10 \\
Air temperature, ${ }^{\circ} \mathrm{C}$ & ROTRONIC PT100 BAV99 & $0-100$ & \pm 0.2 \\
Relative humidity, $\%$ & ROTRONIC HYGROMETER CK60 & $-40+70$ & \pm 5 \\
Sea surface temperature (SST), ${ }^{\circ} \mathrm{C}$ & PT100 Engelhard Pyrocontrole & $0-2800$ & $\pm 0.2 \%$ \\
Shortwave radiation $(0.285-2.8 \mu \mathrm{m}), \mathrm{W} \mathrm{m}^{-2}$ & Pyranometer EPPLEY PSP & $0-700$ & $\pm 3 \%$ \\
Longwave radiation $(3.5-50 \mu \mathrm{m}), \mathrm{W} \mathrm{m}^{-2}$ & Radiometer EPPLEY PIR & $\pm 3 \%$ \\
\hline
\end{tabular}

${ }^{\mathrm{a}}$ Sensors were at $4.5 \mathrm{~m}$ above sea level, and the SST sensor was at $-1 \mathrm{~m}$.

resolution of the input observables (Kent et al. [1993] and Gulev [1997] indicate that the method of space-time averaging is one of the most important contributors to differences between flux fields); and (3) to use the best bulk algorithm, as differences in bulk parameterizations can cause significant errors [Zeng et al., 1998; Eymard et al., 1999].

[10] One of the last requisites is to thoroughly validate the final budget obtained, either by comparison with in situ measurements, from buoys [Josey, 2001; Sun et al., 2003; Weller et al., 2004], by indirect validation methods, by running/validating an oceanic model [Caniaux and Planton, 1998], or by the constraint that the budget equations applied to the atmosphere or ocean must balance mass and surface fluxes [Trenberth, 1997; Curry et al., 1999].

[11] The experimental methodology developed during POMME satisfies the three points mentioned above, and is presented in this paper. In a companion paper [Caniaux et al., 2005], the validation of the final budget obtained will be examined, and the realism of fluxes considered.

[12] In section 2, we give an overview of the different data sets used. In section 3, we explain how these data sets were processed to get a synthesized flux for the POMME area (hereafter, these fluxes will be called POMME Flux Estimates and referred to as PFE). The validation of both the input parameters and the fluxes is presented in section 4 through a comparison with the moored buoy and ship data. Finally, section 5 compares the fluxes with the ones obtained with two NWP model fluxes produced by the ECMWF and the French ARPEGE model. The comparisons are done at the moored buoy location, along the ship trajectory and finally over the whole year and area of POMME. Concluding remarks are given in section 6 .

\section{Overview of the Available Data Sets}

[13] In this section the various data sets used are presented. First we describe the data collected from a moored buoy specifically deployed during POMME and the data collected onboard the $\mathrm{R} / \mathrm{V}$ L'Atalante, one of the research vessels involved during $\mathrm{P} 1$ and $\mathrm{P} 2$, which was used to provide validation reference data sets (as described in section 4). We then present the in situ data collected from various kinds of floats and thermosalinographs and the NOAA satellite data used to produce the daily SST fields. Incoming radiative fluxes are retrieved from the satellite METEOSAT. Finally we present the atmospheric fields, necessary to calculate turbulent fluxes, and the Evaporation minus Precipitation (hereafter $E$ - $P$ ) flux (section 2.6) retrieved from the operational ECMWF model analyses.

\subsection{Moored Buoy}

[14] In order to collect air-sea parameters throughout the whole experiment, an anchored buoy was installed at $20.04^{\circ} \mathrm{W}, 41.6^{\circ} \mathrm{N}$, in depths of approximately $2000 \mathrm{~m}$ on the Azores-Biscay ridge. The location of this ridge, on the northwestern part of the POMME domain, explains why the buoy was slightly shifted from the center of the POMME field.

[15] The moored buoy was of Ocean Data Acquisition System (ODAS) type and was equipped with traditional sensors for measuring air temperature and relative humidity at $4.5 \mathrm{~m}$ high, barometric pressure, wind velocity and direction, SST and swell (Table 1 gives the technical references and accuracy of instruments). Incident longwave and shortwave radiation was also measured from sensors specially installed by the technical teams of the Centre National de Recherches Météorologiques (CNRM).

[16] Air-sea parameters were averaged over $10 \mathrm{~min}$ and then transmitted every hour, and the acquisition frequency for the longwave and shortwave radiation was $10 \mathrm{~min}$. The buoy was installed on 26 August 2000. Owing to power supply problems, the air-sea parameter acquisition frequency had to be reduced to 3 hours in February 2001. The buoy definitively stopped emitting on 4 May 2001 so that the data set was reduced to 8 months, instead of the 1 year envisaged. Radiative fluxes, which had an independent power supply, were recorded with no interruptions every $10 \mathrm{~min}$ from September to May, when the buoy was recovered.

\subsection{Equipped Mast on the $\mathrm{R} / \mathrm{V}$ L'Atalante}

[17] During P1 and P2, a meteorological instrument package was specially implemented at the top of a mast, roughly $18 \mathrm{~m}$ above the sea surface, located on the foredeck of the $\mathrm{R} / \mathrm{V}$ L'Atalante, one of the ships involved in the hydrological surveys. This package provided measurements for shortwave and longwave radiation, mean atmospheric parameters and turbulence. Radiation sensors were gimballed to maintain a level position in order to reduce uncertainties. Turbulence was measured for estimating turbulent fluxes (wind stress, latent and sensible heat) by the inertial dissipation and eddy correlation methods (these methods are discussed by Fairall et al. [1997] and McGillis et al. [2001]).

[18] Mean atmospheric parameters (wind, air temperature and relative humidity, atmospheric pressure, precipitation and radiative fluxes) were continuously recorded by two 
Table 2. List of Sensors Mounted on the Instrumented Mast Onboard the R/V L'Atalante for Mean Atmospheric Parameters $^{\mathrm{a}}$

\begin{tabular}{lcc}
\hline \multicolumn{1}{c}{ Parameter } & Sensor & Accuracy \\
\hline Pressure, $\mathrm{hPa}$ & VAISALA PTB 220 & \pm 3 \\
Wind velocity, $\mathrm{m} \mathrm{s}^{-1}$ & YOUNG 05106 & \pm 0.3 \\
Wind direction, deg & YOUNG 05106 & \pm 3 \\
Air temperature, ${ }^{\circ} \mathrm{C}$ & VAISALA HMP233 & \pm 0.1 \\
Relative humidity, \% & VAISALA HMP233 \\
Shortwave radiation $(0.305-2.8 \mu \mathrm{m}), \%$ & Pyranometer KIPP and Zonen CM3 \\
Longwave radiation $(5-50 \mu \mathrm{m}), \mathrm{W} \mathrm{m}{ }^{-2}$ & Pyrgeometer KIPP and Zonen CG1 \\
Precipitation, \% & SCTI ORG-115 & 3 \\
Sound velocity, $\%$ & Sonic anemometer & 15 \\
$\mathrm{U}, \mathrm{V}, \mathrm{W}, \%$ & & 10 \\
\hline
\end{tabular}

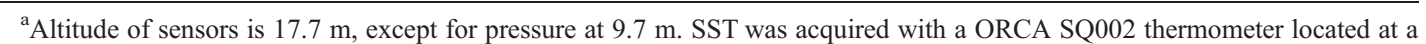
depth of $3.5 \mathrm{~m}$ at the head of the $\mathrm{R} / \mathrm{V}$ L'Atalante.

independent instrument systems (Table 2); SST was also acquired continuously with an ORCA SQ 002 thermometer. The period of measurement began on 2 February and ended on 11 May and was solely interrupted for short stops on the island of São Miguel (Azores Archipelago), Lisbon and São Miguel again, respectively from 23 to 27 February, 14 to 20 March, and 12 to 15 April. The acquisition frequency was $10 \mathrm{~s}$, and observables were then averaged every $10 \mathrm{~min}$ to produce a data file. More details on the instruments, methodology and data processing can be found in a technical note [Prigent, 2003] and a reference paper [Weill et al., 2003].

\subsection{In Situ Sea Surface Temperature}

[19] Numerous surface data sets were collected during POMME from several platforms: thermosalinographs onboard research vessels ( $\mathrm{R} / \mathrm{V}$ La Thalassa, R/V L'Atalante) involved in the different POMME intensive observing periods (IOP); thermosalinographs from Voluntary Observation Ship (VOS) cruising the area and measurements from several drifters specially launched during the experiment (52 SVP and 19 SURDRIFT drifters; 21 MARISONDE and 4 CARIOCA buoys; 6 PROVOR and 8 VCM floats measuring vertical temperature profiles including SST). MARISONDE, CARIOCA and SURDRIFT buoys were launched during the first leg of P1 and provided SST every hour. Tables 3 and 4 give the number of SST values collected by each type of platform and drifters. All these data sets were gathered, processed and calibrated after the experiment before producing specific SST analyses that were then merged with satellite data.

\subsection{Satellite Sea Surface Temperature}

[20] Advanced Very High Resolution Radiometer (AVHRR) data (measuring emitted and reflected radiation at visible and infrared wavelengths $(0.6,0.9,3.7,10.5$ and $11.50 .6 \mu \mathrm{m})$ ) from the NOAA-14 and NOAA-15 satellites was used for SST. The data processing was carried out daily at the Centre de Météorologie Spatiale (CMS) of Lannion (Bretagne, France) with the same method applied for GOES-8 by Brisson et al. [2002]. The POMME zone was covered twice a day by each satellite, in the morning and in the evening. Along the satellite track and with a clear sky, pixel data was available nearly every kilometer, on the satellite-specific grid.

\subsection{Satellite Radiative Heat Fluxes}

[21] Downward shortwave and longwave fluxes were estimated from METEOSAT data with the method described by Brisson et al. [1994]. This method is based on a simplified radiative transfer model and the cloud cover effect is taken into account through empirical parameterizations. Radiative fluxes obtained with this method have already been evaluated during previous experiments [Weill et al., 2003]. The results indicated that such radiative fluxes are much better than those predicted by NWP models and are very efficient for reconstructing radiative fluxes at the mesoscale at midlatitudes and in the Tropics. Data was

Table 3. Number of Data Processed per R/V and VOS That Measured SST

\begin{tabular}{lccc}
\hline \multicolumn{1}{c}{ R/V + VOS } & 2000 & 2001 & Total \\
\hline COLIBRI & 454 & 2146 & 2600 \\
LONDON & 260 & 541 & 801 \\
ELVZ5 & 191 & 318 & 509 \\
ELVZ6 & 333 & 0 & 333 \\
PASTEUR & 507 & 1721 & 2228 \\
TOUCAN & 1947 & 3573 & 5520 \\
WATERBERG & 28 & 53 & 81 \\
R/V L'Atalante & 0 & 13,976 & 13,976 \\
R/V La Thalassa & 4630 & 6603 & 11,233 \\
R/V D'Entrecastaux & 112 & 533 & 645 \\
AILLETTE (xbt) & 0 & 17 & 17 \\
ELVX4 (xbt) & 1 & 0 & 1 \\
FNAV0 (xbt) & 27 & 26 & 53 \\
FNOR0 (xbt) & 0 & 20 & 20 \\
FNOU0 (xbt) & 0 & 23 & 23 \\
Total (15) & $\mathbf{8 4 9 0}$ & $\mathbf{2 9 , 5 5 0}$ & $\mathbf{3 8 , 0 4 0}$ \\
\hline
\end{tabular}

\footnotetext{
${ }^{\mathrm{a}}$ The period considered extends from 1 September 2000 to 31 October 2001 in the domain $23.8^{\circ}-12.9^{\circ} \mathrm{W}$ and $34.5^{\circ}-48.5^{\circ} \mathrm{N}$.
} 
Table 4. Number of Data Processed Per Instrument Measuring SST ${ }^{\mathrm{a}}$

\begin{tabular}{lccc}
\hline \multicolumn{1}{c}{ Drifters } & 2000 & 2001 & Total \\
\hline Moored buoy (1) & 1010 & 943 & 1953 \\
CARIOCA (4) & 0 & 15,573 & 15,573 \\
MARISONDE (20) & 0 & 57,218 & 57,218 \\
Sescan (1) & 5 & 40 & 45 \\
PROVOR (6) & 5 & 224 & 229 \\
Seasoar (1) & 0 & 2175 & 2175 \\
SURDRIFT (19) & 6879 & 26,531 & 33,410 \\
VCM (8) & 0 & 695 & 695 \\
SVP (32) & 18,652 & 27,100 & 45,752 \\
Total & $\mathbf{2 6 , 5 5 1}$ & $\mathbf{1 3 0 , 4 9 9}$ & $\mathbf{1 5 7 , 0 5 0}$ \\
\hline
\end{tabular}

${ }^{\mathrm{a}}$ The period considered extends from 1 September 2000 to 31 October 2001 in the domain $23.8^{\circ}-12.9^{\circ} \mathrm{W}$ and $34.5^{\circ}-48.5^{\circ} \mathrm{N}$.

processed operationally by CMS. Fluxes are available every hour with a spatial resolution of 0.04 degrees of longitude/ latitude for the shortwave flux and 0.08 degrees for longwave fluxes.

\subsection{Atmospheric Parameters}

[22] The bulk flux algorithm used to compute the sensible and latent heat, momentum and $E-P$ requires the following atmospheric parameters: surface wind speed, air temperature and humidity, sea level pressure and precipitation rates. These atmospheric parameters were extracted from the ECMWF IFS operational weather forecast model. The version used is the spectral T213/L31 model with a 4D-VAR assimilation system in a 6 hour cycling [Rabier et al., 1998]. The approximate grid spacing of the model is about $50 \mathrm{~km}$ at the latitude of the POMME area. Analyses of air temperature at $2 \mathrm{~m}$ height, sea surface pressure, dew point temperature at $2 \mathrm{~m}$, wind at $10 \mathrm{~m}$ and precipitation are available every 6 hours on a regular grid $(0.5$ degree of latitude and longitude) and were extracted from the Meteorological Archive and Retrieval System (MARS).

\section{Processing of the Data Sets}

\subsection{Turbulence Measurements and the Bulk Algorithm Used}

[23] A large data set of turbulence measurements was collected during the first legs of $\mathrm{P} 1$ and $\mathrm{P} 2$ onboard the $\mathrm{R} / \mathrm{V}$ L'Atalante (6 weeks), in a wide range of atmospheric and sea state conditions. These measurements were used to provide the bulk algorithm used in this study. Turbulent fluxes from both the classical eddy correlation and inertiodissipative methods were derived with the given instrumental setup. Since the flux computation was performed using the same methodology and algorithms developed during another experiment (EQUALANT99 in the tropical Atlantic) we refer to the detailed description of the methods by Brut [2002] and Brut et al. [2005]. Only a brief description of the main steps for processing the data is described here.

[24] The airflow distortion induced by the ship and instrument package was preliminarily studied at CNRM by means of a physical simulation in a large water channel. To precisely quantify the effect of airflow distortion, a detailed model of the $\mathrm{R} / \mathrm{V}$ L'Atalante and its instrumented mast at a 1/60 scale was placed in a water flow channel with varying angles using the technique described by Butet [2002]. The physical simulations provided discrete correction coefficients for the mean wind speed according to the wind direction with respect to the ship axis. These correc- tions were applied to the mean wind measurements as by Brut et al. [2005]. In the case of POMME, the impact of airflow distortion due to the ship structure increases the wind speed by $6 \%$ and therefore tends to decrease the neutral drag coefficient $C d_{n}$ by up to $29 \%$, in agreement with results from earlier experiments [Dupuis et al., 2003; Brut et al., 2005].

[25] Momentum fluxes and latent heat fluxes were computed using the inertial dissipation method after correcting the mean wind data and sensible heat flux with the eddy correlation method to derive a state-of-the-art parameterization of $C d_{n}, C e_{n}$ and $C h_{n}$ (neutral transfer coefficient for momentum, latent and sensible heat flux respectively) as a function of $U_{10 n}$, the wind velocity at $10 \mathrm{~m}$, in neutral stratification. Mean values of $C d_{n}, C e_{n}$ and $C h_{n}$ and error bars were computed over wind speed bins of $2 \mathrm{~m} \mathrm{~s}^{-1}$ and the equations of Table 5 are the best least squares linear fits to the data for two different classes of wind velocity (for $C d_{n}$ ) or stability (for $C h_{n}$ ).

[26] A good agreement is obtained when comparing the POMME $C d_{n}$ with Smith [1980], Large and Pond [1981] and Fairall et al. [2003] for winds between 5 and $15 \mathrm{~m} \mathrm{~s}^{-1}$ (Figure 2). Outside this range of values, there is less agreement between the different parameterizations. This could be due to several reasons: the collapse of the assumptions underlying the inertial dissipation method at low wind speeds [Yelland and Taylor, 1996]; the impact of boundary layer convection (gustiness factor [Fairall et al., 1996]; poor data series at low (compare the larger error bars at low wind speeds in Figure 2) or high wind speeds to calibrate the algorithms; the effect of sea state as suggested by the results of the HEXOS experiment [Smith et al., 1992]. With regards to the neutral exchange coefficient for evaporation (Table 5), a linear increase of $C e_{n}$ with $U_{10 n}$ was adopted as by Brut et al. [2005] and as suggested by other measurements [Dupuis et al., 1997, 2003]. This approach differs from other parameterizations [Large and Pond, 1982; DeCosmo et al., 1996] due to the correction for airflow distortion being necessary [Weill et al., 2003]. Note that this linear tendency of $C e_{n}$ initially observed during the FETCH experiment [Dupuis et al., 2003], has been confirmed over the open ocean in other data sets [Pedreros et al., 2003; Brut et al., 2005]. For $\mathrm{Ch}_{n}$, the data strongly suggests a partition into two classes of stability: constant for stable stratification and decreasing with increasing wind speed for unstable stratification. Higher $C h_{n}$ values are obtained compared to Large and Pond [1982] and DeCosmo et al. [1996] (Table 5). These differences may be due to uncertainties associated to low air-sea temperature differences and low 
Table 5. Comparison of $C d_{n}, C h_{n}$, and $C e_{n}$ Transfer Neutral Coefficients (For the Wind Stress, Sensible, and Latent Heat, Respectively) Used in the Present Study and in Different Bulk Formulae $^{\mathrm{a}}$

\begin{tabular}{|c|c|c|}
\hline$C d_{n} \times 10^{3}$ & $C h_{n} \times 10^{3}$ & $C e_{n} \times 10^{3}$ \\
\hline $\begin{array}{l}1.246-0.0554 U_{10 n} \\
\left(U_{10 n} \leq 6.3\right) \\
0.387+0.0809 U_{10 n} \\
\left(U_{10 n} \geq 6.3\right)\end{array}$ & $\begin{array}{c}\text { Present Study } \\
1.616 \\
(z / L \geq 0) \\
1.239-0.0363 U_{10 n} \\
(z / L \leq 0)\end{array}$ & $0.63+0.055 U_{10 n}$ \\
\hline $\begin{array}{l}1.14 \\
\left(U_{10 n} \leq 10\right) \\
0.49+0.065 U_{10 n} \\
\left(U_{10 n} \geq 10\right)\end{array}$ & $\begin{array}{c}L P 81 / 82 \\
0.66 \\
(z / L \geq 0) \\
1.13 \\
(z / L \leq 0)\end{array}$ & 1.15 \\
\hline $\begin{array}{l}0.93 \\
\left(U_{10 n} \leq 5\right) \\
0.61+0.063 U_{10 n} \\
\left(U_{10 n} \geq 5\right)\end{array}$ & $\begin{array}{l}S C 80 / 96 \\
0.83 \\
(z / L \geq 0) \\
1.10 \\
(z / L \leq 0)\end{array}$ & 1.12 \\
\hline $\begin{array}{l}0.75+0.054 U_{10 n} \\
\left(5 \leq U_{10 n} \leq 10\right) \\
0.48+0.082 U_{10 n} \\
\left(10 \leq U_{10 n} \leq 17\right) \\
0.84+0.061 U_{10 n} \\
\left(17 \leq U_{10 n} \leq 20\right)\end{array}$ & $\begin{array}{c}F 03 \\
1.09+0.003 U_{10 n} \\
\left(5 \leq U_{10 n} \leq 10\right) \\
1.00+0.011 U_{10 n} \\
\left(10 \leq U_{10 n} \leq 17\right) \\
1.05+0.009 U_{10 n} \\
\left(17 \leq U_{10 n} \leq 20\right)\end{array}$ & $\begin{array}{l}1.09+0.003 U_{10 n} \\
\left(5 \leq U_{10 n} \leq 10\right) \\
1.00+0.011 U_{10 n} \\
\left(10 \leq U_{10 n} \leq 17\right) \\
1.05+0.009 U_{10 n} \\
\left(17 \leq U_{10 n} \leq 20\right) \\
\end{array}$ \\
\hline
\end{tabular}

${ }^{a}$ Bulk formulae are LP81/82 [Large and Pond, 1981, 1982]; SC80/96 [Smith, 1980; DeCosmo et al., 1996], and F03 [Fairall et al., 2003]. Value $\frac{z}{L}$ corresponds to the Obukhov stability parameter, with $z$ being the height of the temperature measurement and $L$ the Monin-Obukhov length.

sensible heat flux values. Even with technical improvements of the measurement device, strong uncertainties remain with regards to determining $\mathrm{Ch}_{n}$ [Weill et al., 2003].

[27] This parameterization has been used for computing the turbulent fluxes of the moored buoy, the R/V L'Atalante and of the PFE. Sensitivity tests to the previously quoted parameterizations are also presented in the next sections.

\subsection{Computation of Ship and Buoy Fluxes}

[28] The turbulent fluxes of the moored buoy were computed from hourly observables with the POMME bulk parameterization presented previously. A stabilitydependent height correction has been applied to the buoy to adjust wind, humidity and temperature to the height of the NWP model analyses $(10 \mathrm{~m}$ for the wind and $2 \mathrm{~m}$ for air temperature and humidity). Both ship and buoy moisture sensors measured the relative humidity whereas the $2 \mathrm{~m}$ dew point temperature is the available ECMWF moisture parameter. In order to make the comparison, the following conversion formula has been used [Murray, 1967]:

$$
q=\frac{\exp \left(17.269 * T_{d p} /\left(T_{d p}+273.16-35.86\right)\right)}{\exp (17.269 * T /(T+273.16-35.86))},
$$

where $T_{d p}$ and $T$ are respectively the dew point temperature and air temperature in degrees Celsius.

[29] Ship turbulent fluxes were estimated using $10 \mathrm{~min}$ averages of the basic observables and the POMME bulk flux parameterization. Recent studies on the optimal duration over which ship fluxes are computed by the bulk method suggest a 10 min average because this frequency contains most of the small-scale energy [Eymard et al., 2003]. As explained in section 3.1, corrections for airflow distortion were applied to the mean $10 \mathrm{~min}$ wind speed before computing the fluxes. As for the moored buoy, a stability-dependent height correction was applied to adjust wind, humidity and temperature to the height of the NWP model analyses. Model observables and fluxes were then linearly interpolated at the successive positions of the ship along its trajectory every 6 hours as in Eymard et al. [1999].

[30] The accuracy of the fluxes from the moored buoy and ship data sets has been evaluated by using the potential biases of the basic observables in Tables 1 and 2 and the long-term mean for the other observables. Results are reproduced in Table 6. If these errors cumulate, we obtain $23 \mathrm{~W} \mathrm{~m}^{-2}$ (buoy) and $14 \mathrm{~W} \mathrm{~m}^{-2}$ (ship) for latent heat, $3 \mathrm{~W} \mathrm{~m} \mathrm{~m}^{-2}$ and $2 \mathrm{~W} \mathrm{~m}^{-2}$ for sensible heat and $0.016 \mathrm{~N} \mathrm{~m}^{-2}$ and $0.011 \mathrm{~N} \mathrm{~m}^{-2}$ for wind stress. For the shortwave and longwave fluxes we obtain $12 \mathrm{~W} \mathrm{~m}^{-2}$ (buoy and ship) and $11 \mathrm{~W} \mathrm{~m}^{-2}$ (buoy) and $15 \mathrm{~W} \mathrm{~m}^{-2}$ (ship). Note that the biases often partially balance each other [Moyer and Weller, 1997] so that these figures must be considered as extreme limits on the error.

\subsection{Sea Surface Temperature Analyses}

[31] The net longwave radiative, sensible, latent heat fluxes depend on the surface temperature of the ocean and the mesoscale SST field is an important component for reconstructing all these fluxes. According to the results of past experiments [Giordani et al., 1998; Giordani and Caniaux, 2001] SST present small-scale structures which significantly affect surface fluxes and therefore the atmospheric boundary layer. Similarly, Gao et al. [2003] indicated that the use of fine temporal and spatial scale SST strongly modify surface fluxes. These studies demonstrate the need of improving SST fields for reconstructing mesoscale fluxes.

[32] Thus specific SST analyses merging satellite data and in situ data were produced daily with a spatial resolution of $5 \mathrm{~km}$, corresponding to the grid spacing that had been chosen for mesoscale models to simulate the surface layers during POMME [Paci et al., 2005; Lévy et al., 2005; Giordani et al., 2005]. This resolution was adopted for reconstructing all the flux fields presented in this paper. SST fields were thus reconstructed to compute the PFE (POMME flux estimates), and to provide validation fields for the different models used in POMME.

[33] An optimal interpolation algorithm was used to merge in situ data to specific guess fields obtained from satellite data with a procedure quite similar to that used by Reynolds and Smith [1994]. Only morning (00 hours to 10 hours) satellite and in situ data was used to avoid spurious effects associated with the diurnal cycle of SST. The abundance of satellite data makes it possible to obtain SST guess fields covering the POMME domain every 3 days, with very few points lacking. Optimal analyses were then performed every 3 days from the satellite guess fields by including all the available in situ SST data. Finally a linear interpolation was used to get one SST analysis every day. The detailed procedure adopted to process the SST data and the analyses is described in Appendix A. 


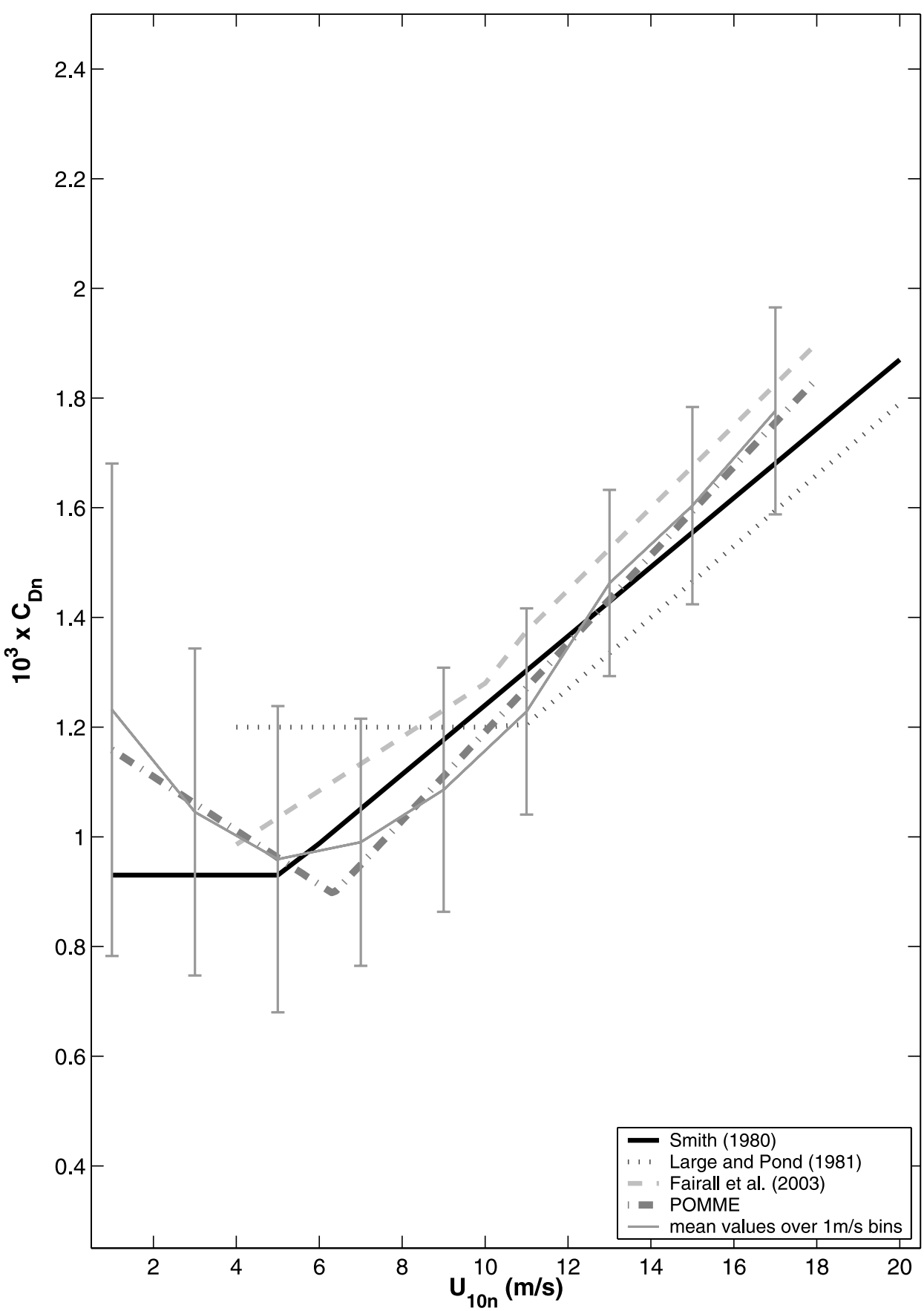

Figure 2. Coefficient $C d_{n}$ of the POMME parameterization (error bars represent the values of $C d_{n}$ over wind speed bins of $2 \mathrm{~m} \mathrm{~s}^{-1}$ ) as a function of the wind velocity at $10 \mathrm{~m}$ and in neutral stratification compared to other classical parameterizations.

\subsection{Determination of Flux Fields}

\subsubsection{Radiative Flux Fields}

[34] Satellite data (incoming shortwave and longwave radiation) was processed to obtain daily fields by averaging the hourly pixel fields. Daily fields were then scaled on to the $5 \mathrm{~km}$ mesh grid. This procedure consists in averaging all the available pixels within $5 \mathrm{~km}$ of each grid point. Net longwave fluxes $\left(F_{\mathrm{LW}}\right)$ were then obtained from the daily incoming longwave radiation $\left(F_{\text {DLW }}\right)$ and daily analyzed $\mathrm{SST}$ fields (in ${ }^{\circ} \mathrm{C}$ ) by the classical formula

$$
F_{\mathrm{LW}}=(1-\alpha) F_{\mathrm{DLW}}-\epsilon \sigma(\mathrm{SST}+273.16)^{4},
$$

where $\alpha$ is the longwave reflectance $(0.045)$ taken from Bignami et al. [1995], $\epsilon$ is the longwave emissivity $(0.97)$ and $\sigma$ is the Stefan-Boltzmann constant $(5.67 \times$ 
Table 6. Estimated Accuracy of Turbulent Fluxes Deduced From the Uncertainties of Instrumental Bias at the Buoy and the Ship Shown in Tables 1 and 2

\begin{tabular}{|c|c|c|c|}
\hline & $F_{\mathrm{LAT}}, \mathrm{W} \mathrm{m}^{-2}$ & $F_{\mathrm{SEN}}, \mathrm{W} \mathrm{m}^{-2}$ & Stress, $\mathrm{N} \mathrm{m}^{-2}$ \\
\hline \multicolumn{4}{|c|}{ Buoy } \\
\hline Air temperature & 3.7 & 2.2 & 0.0012 \\
\hline SST & 0.7 & 0.3 & 0.0002 \\
\hline Relative humidity & 15.0 & 0.0 & 0.0006 \\
\hline Wind & 2.9 & 0.4 & 0.0141 \\
\hline \multicolumn{4}{|c|}{ Ship } \\
\hline Air temperature & 1.8 & 1.3 & 0.0005 \\
\hline SST & 0.7 & 0.4 & 0.0001 \\
\hline Relative humidity & 8.9 & 0.1 & 0.0002 \\
\hline Wind & 2.3 & 0.5 & 0.0102 \\
\hline
\end{tabular}

$\left.10^{-8} \mathrm{~W} \mathrm{~m}^{-2} \mathrm{~K}^{-4}\right) . F_{\mathrm{RAD}}$, the net radiation flux at the surface was obtained as the sum of $F_{\mathrm{LW}}$ and shortwave incoming radiation $\left(F_{\mathrm{SW}}\right)$, to which a fraction is removed corresponding to the reflected shortwave radiation assuming a constant albedo (0.06).

\subsubsection{Turbulent Flux Fields}

[35] Latent, sensible and momentum fluxes were calculated with the preceding bulk parameterization from analyzed atmospheric ECMWF fields (air temperature at $2 \mathrm{~m}$, dew point temperature at $2 \mathrm{~m}$, wind at $10 \mathrm{~m}$, sea level pressure and precipitation) and from the analyzed SST fields. ECMWF analyses are available every 6 hours on a $0.5^{\circ}$ mesh grid. These data were first linearly interpolated onto the $5 \mathrm{~km}$ mesh grid, then fluxes were computed every 6 hours and finally daily averaged. The net heat flux is calculated as follows:

$$
F_{\mathrm{NET}}=F_{\mathrm{RAD}}+F_{\mathrm{LAT}}+F_{\mathrm{SEN}}
$$

where $F_{\mathrm{RAD}}$ is the net radiative flux, $F_{\mathrm{LAT}}$ the latent heat flux and $F_{\mathrm{SEN}}$ the sensible heat flux with the convention that a positive flux corresponds to a warming of the oceanic surface. 3.4.3. $\quad E-P$ Fields

[36] Evaporation was deduced from the latent heat fluxes determined previously and precipitation derived from ECMWF operational analyses, as for the other atmospheric variables. The $E-P$ budget was stored daily, given by the formula

$$
E-P=-\frac{F_{\mathrm{LAT}}}{\rho L_{v}}-P
$$

where $L_{v}$ is the latent heat of vaporization and $\rho$ the density of pure water. Latent heat $F_{\text {LAT }}$ is expressed in $\mathrm{W} \mathrm{m}^{-2}$ and precipitation $P$ in $\mathrm{m} \mathrm{s}^{-1}$. Note that the hydrological cycle in the ECMWF analyses is marked by excessive precipitation over the ocean when compared to climatologies [Arpe and Roeckner, 1999; Beranger et al., 1999]. Scores have been found to be worse in the Tropics [Lim and Ho, 2000]. For the extra-Tropics, some studies indicate $10 \%$ higher values with a tendency of a balance between precipitation and evaporation [Beranger et al., 1999].

\section{Validation of Observables and Fluxes \\ 4.1. Validation of Atmospheric Parameters}

[37] The ECMWF observables are compared with those of the buoy over 8 months ( 894 samples of 6 hour instantaneous data) and the ship over 4 months (325 samples of 6 hour data) with the aim of judging their quality for computing the PFE. For the buoy (the ship) data the statistics are shown on Table 7 (Table 8) and Figure 3 (Figure 4) displays the meteorological/oceanic parameters collected.

\subsubsection{Air Temperature}

[38] Both buoy air temperature and SST decreased from $21^{\circ} \mathrm{C}$ to $13^{\circ} \mathrm{C}$ from September to December and then stayed rather unchanged before increasing slightly in April to $14^{\circ} \mathrm{C}$ (Figures $3 \mathrm{a}$ and $3 \mathrm{~b}$ ). The bias (buoy minus model) of air temperature $\left(-0.12^{\circ} \pm 0.02^{\circ} \mathrm{C}\right)$ indicates a weak overestimate of the model with a correlation coefficient of 0.97 (Table 7). The comparison of model air temperature with the ship indicates a larger overestimate of the model $\left(-0.60^{\circ} \pm\right.$ $0.03^{\circ} \mathrm{C}$ ) with a poorer correlation of 0.88 (Table 8 ), though the ship and buoy data compare well when they were close by during two short periods.

\subsubsection{Winds}

[39] Peak winds recorded on the buoy were larger during the winter months, with maxima exceeding $15 \mathrm{~m} \mathrm{~s}^{-1}$ during storm conditions (Figure 3c). Winds recorded on the ship were on average close to $9 \mathrm{~m} \mathrm{~s}^{-1}$, with maxima exceeding $15 \mathrm{~m} \mathrm{~s}^{-1}$ in February, March, and April (Figure 4c). On average the corrected $10 \mathrm{~m}$ high winds of the buoy were slightly weaker than the ECMWF ones $\left(-0.26 \pm 0.05 \mathrm{~m} \mathrm{~s}^{-1}\right.$ (Table 7)) with instantaneous differences often exceeding $\pm 3 \mathrm{~m} \mathrm{~s}^{-1}$, reflecting the high-frequency variability of wind measurements.

[40] The ECMWF model winds were weaker than ship winds (ship model difference of $0.64 \pm 0.08 \mathrm{~m} \mathrm{~s}^{-1}$ (Table 8)). The correlation between model time series and both the buoy and ship measurements are quite satisfactory (0.90). A comparison of ECMWF winds with buoy observations during TOGA/COARE was done by Weller and Anderson [1996] and they found an underestimate of the model wind intensity.

\subsubsection{Sea Level Pressure}

[41] The sea level pressure on the buoy was on average $1016 \mathrm{hPa}$ for the period considered but varied from $1037 \mathrm{hPa}$ to $975 \mathrm{hPa}$ (Figure 3e). Note that the ship experienced the same extrema with a maximum at $1036 \mathrm{hPa}$ and a minimum of $975 \mathrm{hPa}$ during the same storm in March (Figure 4e). Generally this parameter is very well reconstructed in NWP models [Dourado and

\begin{tabular}{|c|c|c|c|c|c|}
\hline & Buoy (rms) & ECMWF (rms) & Bias, Standard Error Difference (\%) & rms Difference & Correction \\
\hline Air temperature, ${ }^{\circ} \mathrm{C}$ & $15.39(2.73)$ & $15.51(2.77)$ & $-0.12 \pm 0.02(0.7)$ & 0.65 & 0.97 \\
\hline Pressure, $\mathrm{hPa}$ & $1016.41(11.27)$ & $1016.21(11.55)$ & $0.20 \pm 0.03(0.0)$ & 1.01 & 1.00 \\
\hline Dew point, ${ }^{\circ} \mathrm{C}$ & $12.36(3.49)$ & $12.01(3.62)$ & $0.35 \pm 0.03(2.9)$ & 0.97 & 0.97 \\
\hline Relative humidity, $\%$ & $82.69(10.07)$ & $80.16(9.63)$ & $2.53 \pm 0.18$ & 5.92 & 0.85 \\
\hline Wind, $\mathrm{m} \mathrm{s}^{-1}$ & $8.31(3.55)$ & $8.57(3.64)$ & $-0.26 \pm 0.05(3.1)$ & 1.65 & 0.90 \\
\hline
\end{tabular}

Table 7. Comparison Buoy-European Centre for Medium-Range Weather Forecasts (ECMWF) 6 Hour Atmospheric Variables ${ }^{\mathrm{a}}$

${ }^{\mathrm{a}} N=894$. The period of comparison is from 1 September 2000 to 4 May 2001 
Table 8. Comparison of Atmospheric Parameters From ECMWF and the Instrumented Mast of R/V L'Atalante (From P1 to P2, 2 February 2001 to 11 May 2001) ${ }^{\mathrm{a}}$

\begin{tabular}{|c|c|c|c|c|c|}
\hline & Ship (rms) & ECMWF (rms) & Bias, Standard Error of the Difference (\%) & rms of the Difference & Correction \\
\hline Air temperature, ${ }^{\circ} \mathrm{C}$ & $13.49(1.06)$ & $14.09(1.14)$ & $-0.60 \pm 0.03(4)$ & 0.80 & 0.88 \\
\hline Pressure, $\mathrm{hPa}$ & $1018.54(12.31)$ & $1017.75(12.14)$ & $0.79 \pm 0.03(0)$ & 1.00 & 1.00 \\
\hline Relative humidity, \% & $81.42(10.01)$ & $79.84(8.65)$ & $1.58 \pm 0.30(1)$ & 5.67 & 0.84 \\
\hline
\end{tabular}

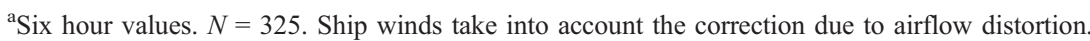

Caniaux, 2001; Eymard et al., 2003], as indicated here with high correlations, weak bias and standard errors (Tables 7 and 8 ).

\subsubsection{Humidity}

[42] If the comparisons of air temperature, wind and sea level pressure can be considered as very satisfactory, one notes contrasting statistics for humidity, either as dew point (model output) or relative humidity (hereafter $\mathrm{RH}$ ) (measured by the buoy) (Table 7). On average, mean differences are respectively $0.35 \pm 0.03^{\circ} \mathrm{C}$ and $2.53 \pm$
$0.18 \%$ with correlations of 0.97 and 0.85 , because errors made on both the air temperature and the dew point temperature are cumulated through the nonlinear formula (1). Note however that the estimated error of moisture measurement (Tables 1 and 2) has a similar magnitude as the bias obtained between the buoy and the model.

[43] The same conclusions are reached from the comparison with the ship data (bias: $1.58 \pm 0.30 \%$; correlation: $0.84)$ where the model underestimates the ship time series (Table 8). Note moreover that RH is the only parameter for
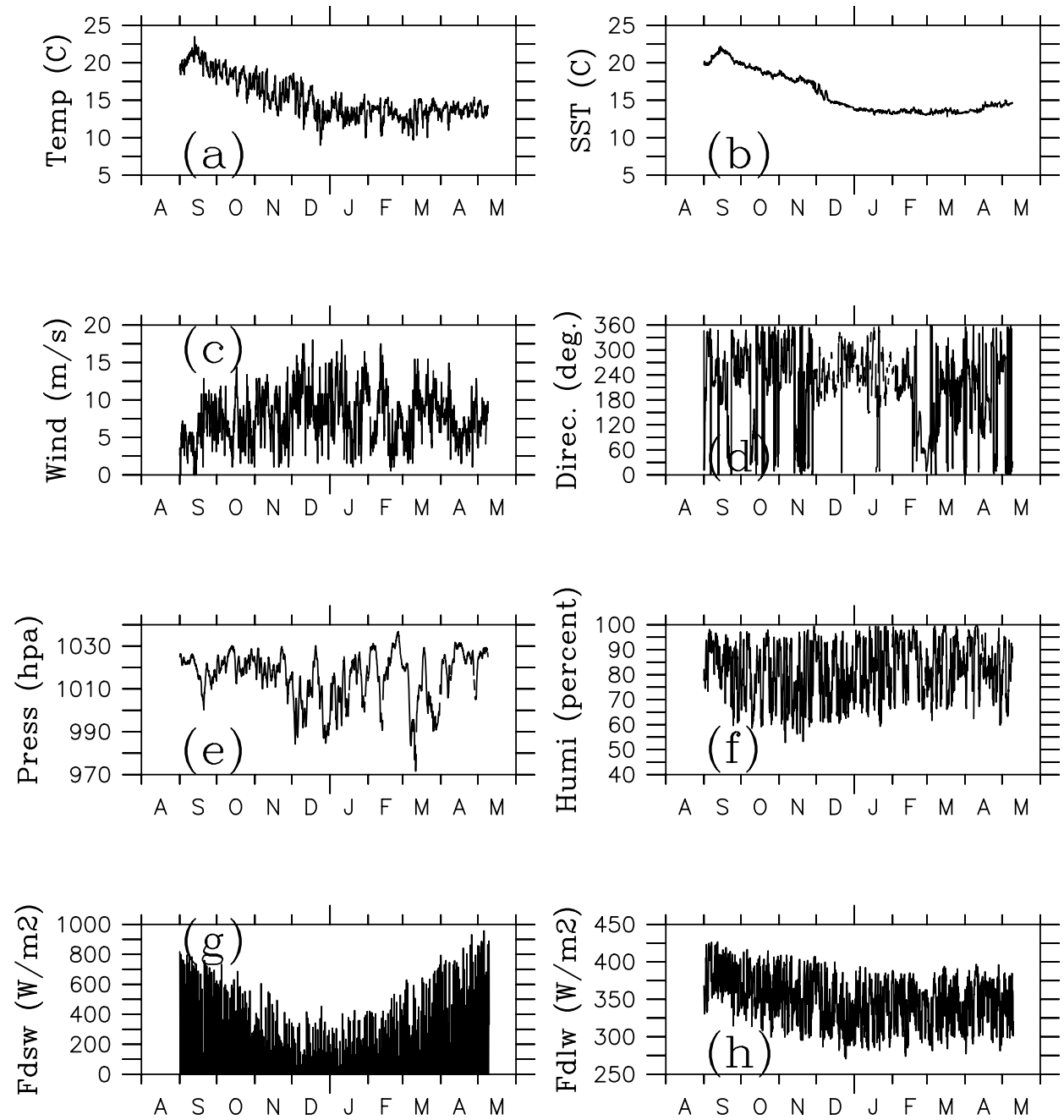

Figure 3. Meteo-oceanic parameters collected by the moored buoy. Data are subsampled here every 3 hours. (a) Two-meter-high air temperature $\left({ }^{\circ} \mathrm{C}\right)$. (b) Sea surface temperature (SST) $\left({ }^{\circ} \mathrm{C}\right)$. (c) Ten-meterhigh wind velocity $\left(\mathrm{m} \mathrm{s}^{-1}\right)$. (d) Wind direction (deg). (e) Sea level pressure (hPa). (f) Two-meter-high relative humidity $(\%)$. (g) Incoming shortwave radiation $\left(\mathrm{W} \mathrm{m}^{-2}\right)$. (h) Incoming longwave radiation $\left(\mathrm{W} \mathrm{m} \mathrm{m}^{-2}\right)$. 

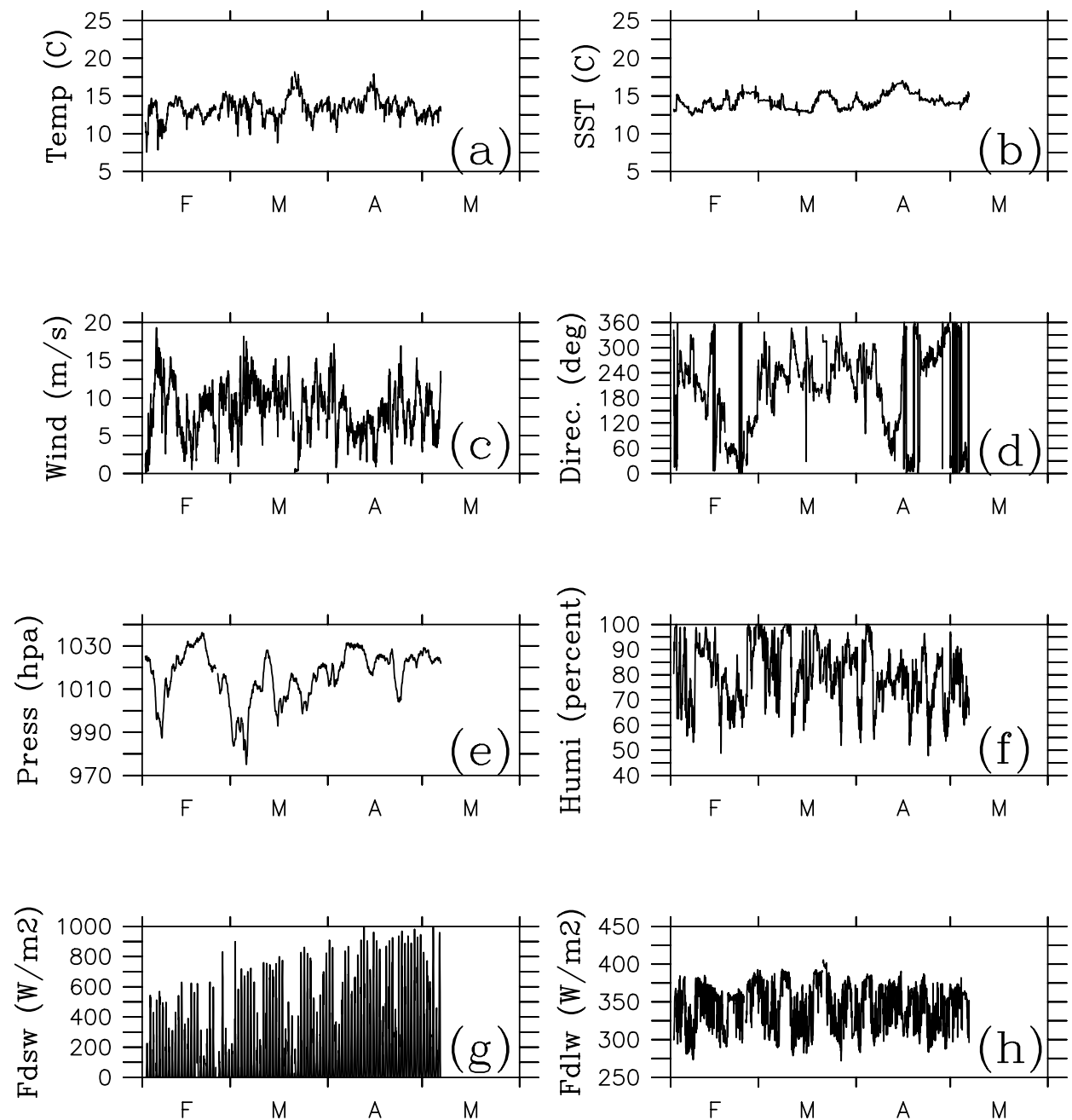

Figure 4. Meteo-oceanic parameters collected onboard the R/V L'Atalante. Data are subsampled every 1 hour. (a) Two-meter-high air temperature $\left({ }^{\circ} \mathrm{C}\right)$. (b) SST $\left({ }^{\circ} \mathrm{C}\right)$. (c) Ten-meter-high wind velocity $\left(\mathrm{m} \mathrm{s}^{-1}\right)$. (d) Wind direction (deg). (e) Sea level pressure (hPa). (f) Two-meter-high relative humidity (\%). (g) Incoming shortwave radiation $\left(\mathrm{W} \mathrm{m}^{-2}\right)$. (h) Incoming longwave radiation $\left(\mathrm{W} \mathrm{m}^{-2}\right)$.

which the comparison with the ship is better than with the buoy, both in term of bias and rms.

\subsubsection{Summary}

[44] The comparisons of ECMWF observables against those at the moored buoy position and those along the ship trajectory have shown that they can be considered as being excellent for deriving fluxes on a large scale. However, the comparisons are slightly better in the case of the buoy than the ship (except for $\mathrm{RH}$ ) in term of bias, rms difference and correlation coefficients. These differences may be due to the following: (1) most of the observations of the buoy being assimilated by the model, which was not the case of the data from the instrumented mast; (2) ship winds have to be corrected for airflow distortion, inducing uncertainties on the direct comparison; and (3) the sampling by the ship being for a specific winter-early spring period whereas the buoy corresponds to August-February, and that the ship covered a quite large region where statistics could be quite different from the ones at the buoy. For a region some degrees of latitude south of the POMME area, Moyer and Weller [1997] pointed out that most of the observables collected by different buoys had significant north-south gradients, leading to contrasting statistics when compared with models outputs.

[45] Note that the comparison errors do not exceed the accuracy of the different sensors on the buoy and the ship. Therefore the comparison can be judged as being fairly good. This brings us to the conclusion that the use of the atmospheric parameters from the ECMWF model, associated with SST fields issued from special reanalyses, should be a reasonable approach for estimating fluxes over the whole POMME area.

\subsection{Validation of Surface Fluxes}

\subsubsection{Radiative Fluxes}

[46] The satellite radiative fluxes are compared with those of the moored buoy on Table 9, where hourly data was averaged daily (246 samples during the period 1 September 2000-4 May 2001). On Tables 10 and 11, daily net satellite shortwave and longwave radiation data is compared with that of the buoy (159 days between 2 September 2000 and 7 February 2001, for which hourly data of the buoy are available) and with that from the ship (73 days between 5 February 2001 and 6 May 2001) respectively. 
Table 9. Comparison of Daily Incoming Shortwave $\left(F_{\mathrm{DSW}}\right)$ and Longwave $\left(F_{\mathrm{DLW}}\right)$ Fluxes From Satellite Estimates and the Anchored Buoy $^{\text {a }}$

\begin{tabular}{|c|c|c|c|c|c|}
\hline & Buoy (rms) & Satellite (rms) & $\begin{array}{l}\text { Bias, Standard Error } \\
\text { of the Difference }(\%)\end{array}$ & rms of the Difference & Correction \\
\hline$F_{\mathrm{DSW}}, \mathrm{W} \mathrm{m}^{-2}$ & $117.16(65.21)$ & $118.45(63.82)$ & $-1.29 \pm 0.70$ & 11.06 & 0.99 \\
\hline$F_{\text {DLW }}, \mathrm{W} \mathrm{m}^{-2}$ & $350.38(23.16)$ & $351.90(19.48)$ & $-1.52 \pm 0.76(0.4)$ & 10.56 & 0.89 \\
\hline
\end{tabular}

${ }^{\mathrm{a} C}$ Calculated from hourly data during the period 1 September 2000 to 4 May 2001. $N=246$.

[47] During the period considered, the incoming longwave radiation fluxes of the buoy fluctuated from $270 \mathrm{~W} \mathrm{~m}^{-2}$ to $425 \mathrm{~W} \mathrm{~m}^{-2}$ (Figure $3 \mathrm{~h}$ ) and incoming shortwave radiation reach peak hourly values up to $900 \mathrm{~W} \mathrm{~m}^{-2}$ (Figure $3 \mathrm{~g}$ ), with mean daily peak values of $312 \mathrm{~W} \mathrm{~m}^{-2}$. For both incident radiative fluxes, very good statistics are obtained since average biases do not exceed $2 \mathrm{~W} \mathrm{~m}^{-2}$ (Table 9). Owing to the large variability of the solar fluxes, the correlation is higher $(99 \%)$ for the shortwave than the longwave $(89 \%)$. Note that satellite fluxes rms (for longwave and shortwave) are somewhat lower than for the buoy estimates, indicating that highfrequency variability mainly associated with cloud cover is larger in the buoy data than in the satellite data. When comparing hourly satellite and buoy shortwave radiation (not shown), biases can frequently occur at sunrise and sunset (up to $50 \mathrm{~W} \mathrm{~m}^{-2}$ with an excess of the satellite compared to the buoy). Owing to the low value of the flux during these periods, their contributions to the mean daily value are small. When comparing daily values of radiation (incoming, outgoing and net) at the buoy (Table 10), similar conclusions are reached, with average biases being smaller than $5 \mathrm{~W} \mathrm{~m}^{-2}$.

[48] Between the P1 and P2 cruises, the ship downward shortwave radiation had instantaneous peak values of up to $1000 \mathrm{~W} \mathrm{~m}^{-2}$ (Figure 4g) and the incoming longwave radiation fluxes fluctuated from $270 \mathrm{~W} \mathrm{~m}^{-2}$ to $400 \mathrm{~W} \mathrm{~m}^{-2}$ (Figure $4 \mathrm{~h}$ ). The mean solar radiation is nearly $150 \mathrm{~W} \mathrm{~m}^{-2}$ (Table 11), which is $60 \mathrm{~W} \mathrm{~m}^{-2}$ higher than the buoy average, reflecting the seasonal variation. Here again, the statistics are excellent, with a bias on average of less than $3 \mathrm{~W} \mathrm{~m}^{-2}$ and correlation coefficient of 0.98 and 0.92 for the net shortwave and net longwave fluxes. Similar results were obtained for METEOSAT irradiances during other experiments at sea, during different seasons and in different basins of the north Atlantic Ocean [Weill et al., 2003]. These results are thought to be good enough to extend the confidence in satellite-derived radiative fluxes at the mesoscale to all seasons.

\subsubsection{Latent Heat Flux}

[49] Latent heat loss is mainly a function of wind speed and the humidity gradient over the sea surface. Over the POMME area, the latent heat flux represents the larger heat loss component of the net heat flux. This flux is highly variable with peak values (down to $-326 \mathrm{~W} \mathrm{~m}^{-2}$ for the buoy data and $-244 \mathrm{~W} \mathrm{~m}^{-2}$ for the ship data) occurring during the winter season. Mean values of $-81 \mathrm{~W} \mathrm{~m}^{-2}$ were obtained for the buoy (Table 10) and somewhat less for the ship $\left(-72 \mathrm{~W} \mathrm{~m}^{-2}\right)$ (Table 11). The latent heat loss of the PFE is underestimated both at the buoy location (bias: $2.6 \pm 2.0 \mathrm{~W} \mathrm{~m}^{-2}$ ) (Table 10 ) and along the ship trajectory (bias: $14.7 \pm 2.1 \mathrm{~W} \mathrm{~m}^{-2}$ ) (Table 11). However the variability of the latent heat flux is quite well reconstructed with correlation coefficients of 0.92 and 0.90 respectively for the buoy and the ship.

\subsubsection{Sensible Heat Flux}

[50] The sensible heat flux is weak compared to the latent heat loss, with $-4 \mathrm{~W} \mathrm{~m}^{-2}$ compared to $-81 \mathrm{~W} \mathrm{~m}^{-2}$ at the buoy location and $-5 \mathrm{~W} \mathrm{~m}^{-2}$ compared to $-72 \mathrm{~W} \mathrm{~m}^{-2}$ for the ship data (Tables 10 and 11 respectively) due to the weak temperature gradient at the sea surface in the POMME area. PFE underestimates the sensible heat loss at the buoy position $\left(6.7 \pm 0.7 \mathrm{~W} \mathrm{~m}^{-2}\right)$ and at the ship position $(10.6 \pm$ $\left.0.8 \mathrm{~W} \mathrm{~m}^{-2}\right)$. As indicated on Tables 10 and 11 , mean PFE values are positive, meaning a heat gain for the ocean. Note that the strongest contribution to the difference on the net heat fluxes is at the buoy position. This discrepancy is due to the underestimate and even reversal of the mean gradient of air temperature and SST. The correlation coefficient is 0.95 with the buoy and 0.94 with the ship.

\subsubsection{Net Heat Flux}

[51] The net heat flux at the buoy is negative during the period of observation $\left(-46 \mathrm{~W} \mathrm{~m}^{-2}\right.$ (Table 10)), indicating a cooling that is expected at this period of the year (fall-winter). During P1-P2, a period that coincided with the beginning of the spring retreat, the ship net heat flux became positive $\left(25 \mathrm{~W} \mathrm{~m}^{-2}\right)$, implying a warming of the ocean due to an excess of net solar warming $\left(150 \mathrm{~W} \mathrm{~m}^{-2}\right)$ over latent heat loss

Table 10. Comparison Between the Daily Fluxes on the Anchored Buoy With POMME and Model Estimates ${ }^{\mathrm{a}}$

\begin{tabular}{|c|c|c|c|c|}
\hline & Buoy & POMME & ARPEGE & ECMWF \\
\hline$\overline{F_{\mathrm{SW}}, \mathrm{W} \mathrm{m}^{-2}}$ & 89.39 & $88.92(-0.47 \pm 0.71)$ & $87.57(-1.82 \pm 2.19)$ & $74.34(-15.05 \pm 2.12)$ \\
\hline$F_{\mathrm{ULW}}, \mathrm{W} \mathrm{m}^{-2}$ & 388.76 & $388.69(0.07 \pm 0.05)$ & & \\
\hline$F_{\text {DLW }}, \mathrm{W} \mathrm{m}^{-2}$ & 353.24 & $357.57(-4.33 \pm 0.83)$ & & \\
\hline$F_{\mathrm{LW}}, \mathrm{W} \mathrm{m}^{-2}$ & -51.42 & $-47.21(4.21 \pm 0.79)$ & $-79.31(-27.89 \pm 1.70)$ & $-49.39(2.03 \pm 0.89)$ \\
\hline$F_{\mathrm{LAT}}, \mathrm{W} \mathrm{m}^{-2}$ & -80.69 & $-78.13(2.56 \pm 2.02)$ & $-120.38(-39.69 \pm 2.55)$ & $-113.95(-33.26 \pm 2.17)$ \\
\hline$F_{\mathrm{SEN}}, \mathrm{W} \mathrm{m}^{-2}$ & -3.55 & $3.10(6.65 \pm 0.68)$ & $2.43(5.98 \pm 0.75)$ & $-12.37(-8.82 \pm 1.06)$ \\
\hline$F_{\mathrm{NET}}, \mathrm{W} \mathrm{m}^{-2}$ & -46.27 & $-33.32(12.95 \pm 2.47)$ & $-109.69(-63.42 \pm 3.22)$ & $-101.37(-55.10 \pm 3.61)$ \\
\hline Stress, $\mathrm{N} \mathrm{m}^{-2}$ & 0.143 & $0.153(0.010 \pm 0.004)$ & $0.173(0.030 \pm 0.005)$ & $0.181(0.038 \pm 0.005)$ \\
\hline$E-P, \mathrm{~mm} \mathrm{~d}^{-1}$ & $\ldots$ & -2.44 & 0.40 & -1.10 \\
\hline
\end{tabular}

${ }^{\text {a}}$ Period is from 2 September 2000 to 7 February 2001. $N=159$. In parentheses are the bias and standard error of the difference with the buoy. $F_{\mathrm{ULW}}$ and $F_{\text {DLW }}$ correspond to the outgoing and incoming longwave radiative fluxes, respectively. 
Table 11. Comparison of Daily Fluxes From the ARPEGE and ECMWF Models and POMME and Fluxes From the R/V L'Atalante

\begin{tabular}{lcccc}
\hline & Ship & POMME & ARPEGE & ECMWF \\
\hline$F_{\text {SW }}, \mathrm{W} \mathrm{m} \mathrm{m}^{-2}$ & 149.96 & $147.05(-2.91 \pm 1.77)$ & $144.17(-5.79 \pm 6.46)$ & $134.78(-15.18 \pm 5.01)$ \\
$F_{\text {ULW }}, \mathrm{W} \mathrm{m}^{-2}$ & 373.80 & $373.54(0.26 \pm 0.06)$ & & \\
$F_{\text {DLW }} \mathrm{W} \mathrm{m} \mathrm{m}^{-2}$ & 340.85 & $340.46(0.39 \pm 1.17)$ & $-76.63(-28.34 \pm 2.52)$ & $-43.70(4.59 \pm 1.70)$ \\
$F_{\mathrm{LW}}, \mathrm{W} \mathrm{m}^{-2}$ & -48.29 & $-48.40(-0.11 \pm 1.11)$ & $-81.89(-10.08 \pm 2.86)$ & $-75.24(-3.43 \pm 1.62)$ \\
$F_{\mathrm{LAT}}, \mathrm{W} \mathrm{m} \mathrm{m}^{-2}$ & -71.81 & $-57.10(14.71 \pm 2.08)$ & $6.74(11.60 \pm 0.80)$ & $-2.68(2.18 \pm 0.99)$ \\
$F_{\text {SEN }}, \mathrm{W} \mathrm{m} \mathrm{m}^{-2}$ & -4.86 & $5.78(10.64 \pm 0.77)$ & $-7.61(-32.61 \pm 5.35)$ & $13.16(-11.83 \pm 4.63)$ \\
$F_{\text {NET }}, \mathrm{W} \mathrm{m} \mathrm{m}^{-2}$ & 25.00 & $47.33(22.33 \pm 2.87)$ & $0.159(0.010 \pm 0.01)$ & $0.159(0.010 \pm 0.00)$ \\
\hline Stress, $\mathrm{N} \mathrm{m}^{-2}$ & 0.149 & $0.124(-0.025 \pm 0.00)$ &
\end{tabular}

${ }^{\text {a }}$ Period is from 5 February 2001 to 6 May 2001. $N=73$. In parentheses are bias and standard errors of the difference with the buoy. $F_{\text {ULw }}$ and $F_{\text {DLW }}$ correspond to the outgoing and incoming longwave radiative fluxes, respectively.

$\left(-72 \mathrm{~W} \mathrm{~m}^{-2}\right.$ (Table 11)). Compared to the buoy fluxes, note that the net longwave and sensible heat fluxes did not change much on average. This can be explained by the small seasonal variation of these two fluxes.

[52] PFE underestimates the heat loss by $13 \pm 2 \mathrm{~W} \mathrm{~m}^{-2}$ at the buoy because of a cumulated underestimate of each component of the non solar heat flux, which is in increasing order: sensible, net longwave and latent heat flux (Table 10).

[53] The comparison of the PFE along the ship trajectory (Table 11) indicates an overestimate of the net heat gain $\left(22.3 \pm 2.9 \mathrm{~W} \mathrm{~m}^{-2}\right)$ mostly due to the underestimate of latent heat and sensible heat. Finally, both comparisons with the buoy and with the ship indicate that the net heat flux is overestimated locally due to the turbulent heat loss being too weak.

\subsubsection{Wind Stress}

[54] At the moored buoy position, wind stress has an average value of $0.143 \mathrm{~N} \mathrm{~m}^{-2}\left(\mathrm{rms}: 0.11 \mathrm{~N} \mathrm{~m}^{-2}\right.$ ) with peak values up to $0.61 \mathrm{~N} \mathrm{~m}^{-2}$ during the winter months. PFE wind stress is largely similar to the buoy differing of only $0.01 \mathrm{~N} \mathrm{~m}^{-2}$ (Table 10), with a similar rms $\left(0.14 \mathrm{~N} \mathrm{~m}^{-2}\right)$ and a correlation coefficient of 0.95 . Note that compared to the ship, the PFE wind stress is underestimated by $0.025 \mathrm{~N} \mathrm{~m}^{-2}$ (Table 11).

\subsubsection{Sensitivity of Fluxes to the Bulk Parameterization}

[55] In this section we compare the POMME parameterization with other published parameterizations. The data set at the moored buoy and from the ship are used in order to investigate the validity of the previous comparisons. Three other parameterization schemes were selected: (1) Large and Pond [1981, 1982] for its frequent use in the literature as well as the broad range of wind values $\left(4-26 \mathrm{~m} \mathrm{~s}^{-1}\right.$ ) used for its calibration; (2) Smith [1980], where wind stresses were derived from an offshore platform in the Nova Scotia area $\left(44^{\circ} \mathrm{N}, 60^{\circ} \mathrm{W}\right)$ by the eddy correlation method at wind speeds ranging from 6 to $22 \mathrm{~m} \mathrm{~s}^{-1}$. As the latent heat flux was not observed, we adopt DeCosmo et al. [1996] $C h_{n}$ and $C e_{n}$ transfer coefficients obtained during the Humidity Exchange Over the Sea (HEXOS) experiment, during which measured wind speeds ranged from 5 to $18 \mathrm{~m} \mathrm{~s}^{-1}$; and (3) Fairall et al. [2003] results from the Tropical Ocean/ Global Atmosphere Coupled Ocean-Atmosphere Response Experiment (TOGA-COARE) that was extended to higher wind speeds (up to $20 \mathrm{~m} \mathrm{~s}^{-1}$ ) from fluxes measured during the NOAA/Environmental Technology Laboratory (ETL) extra-Tropical cruises. Note that the POMME algorithm was issued from flux measurements under winds between 1 and $18 \mathrm{~m} \mathrm{~s}^{-1}$, and numerous stability conditions, including strong stable atmosphere [Weill et al., 2003].

[56] Table 12 presents the mean daily sensible, latent, net heat fluxes and wind stress at the moored buoy and along the ship trajectory obtained with the four parameterizations. We can note that (1) the dispersal due to the use of different bulk formulae is weak and leads to errors that do not exceed $5 \mathrm{~W} \mathrm{~m}^{-2}$; (2) the POMME parameterization slightly overestimates the latent heat and underestimates the sensible heat compared to the other parameterizations; (3) errors may compensate between latent and sensible heat; (4) the influence of the different parameterizations on the net heat flux remains weak (less than 10 percent); (5) Fairall's parameterization overestimates the wind stress compared to the other parameterizations; (6) the use of the POMME param-

Table 12. Comparison of the Daily Turbulent and Net Heat Flux at the Moored Buoy and Along the Ship Trajectory Calculated With Four Different Bulk Parameterizations ${ }^{\mathrm{a}}$

\begin{tabular}{lcccc}
\hline & POMME & LP81/82 & SC80/96 & F03 \\
\hline & & Buoy $(N=159)$ & \\
$F_{\text {LAT }}$ & -80.69 & -79.16 & -76.89 & -76.35 \\
$F_{\text {SEN }}$ & -3.55 & -9.45 & -8.56 & -7.47 \\
$F_{\text {NET }}$ & -46.27 & -50.64 & -47.48 & -45.85 \\
Stress & 0.143 & 0.141 & 0.146 & 0.152 \\
& & & & \\
$F_{\text {LAT }}$ & -71.81 & Ship $(N=73)$ & -67.94 & -67.12 \\
$F_{\text {SEN }}$ & -4.86 & -69.74 & -8.24 & -7.61 \\
$F_{\text {NET }}$ & 25.00 & -8.83 & 25.49 & 26.94 \\
Stress & 0.149 & 23.10 & 0.151 & 0.155 \\
\hline
\end{tabular}

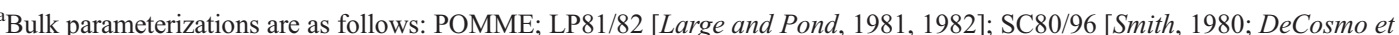
al., 1996]; and F03 [Fairall et al., 2003]. Heat fluxes are in $\mathrm{W} \mathrm{m}^{-2}$; wind stress is in $\mathrm{N} \mathrm{m}^{-2}$. 
eterization is within the margins of error of the other parameterizations used.

\subsubsection{Summary}

[57] It is important to note that the radiative satellite fluxes used for PFE compare very well with in situ data, and that bias in the net heat flux seems to originate predominantly from turbulent fluxes. This will be taken into consideration in a separate paper [Caniaux et al., 2005] in order to investigate whether corrections should be applied to this flux estimate. On the other hand, changing the bulk parameterization used may induce an error of around $5 \mathrm{~W} \mathrm{~m}^{-2}$ onto the average net heat flux from the ship and from the moored buoy data set.

\section{Comparison of Programme Océan Multidisciplinaire Méso Echelle (POMME) Fluxes With Numerical Weather Prediction Model Fluxes}

[58] In this section, PFE are compared with ECMWF and ARPEGE fluxes. The turbulent fluxes of the ECMWF model are computed with the parameterization of Beljaars [1994] and fluxes are archived as cumulated values over 6 hours from 30 hour forecast periods. Time step 12 hour fluxes were decumulated from the ECMWFMARS archive instead of time step 0 hour fluxes in order to avoid the spurious effects of spin-up or spin-down [Ramos-Buarque et al., 2004]. In the same way, fluxes from the French operational forecast ARPEGE model [Courtier et al., 1991] were also extracted. The spectral T106/L31 ARPEGE model had a 3D-VAR assimilation system in operation at the time of POMME with 6 hour cycles. In this model, sea surface fluxes are computed with the Louis et al. [1981] parameterization; the radiation scheme is less sophisticated than in the ECMWF model. Again, fluxes are cumulated over 6 hours and are available on a regular 0.5 degree grid of latitude and longitude.

\subsection{Comparisons at the Moored Buoy Location (Period of Cooling/Deepening)}

\subsubsection{Latent Heat Flux}

[59] From Table 10, the ECMWF and ARPEGE models largely overestimate (respectively: 33 and $40 \mathrm{~W} \mathrm{~m}^{-2}$ ) the latent heat flux loss of the buoy and also of PFE. The heat loss for the ECMWF model is larger by $41 \%$ and $49 \%$ for the ARPEGE model. This result is in agreement with previous studies. Renfrew et al. [2002] noted an overestimate of the latent heat loss in the ECMWF model of approximately $50 \%$ in the Labrador Sea, by comparing the fluxes measured onboard of a research vessel. Josey [2001] found an overestimate of $16 \%$ and Weller et al. [2004] of $12 \%$ in the southern zone of the POMME area between the ECMWF model and moored buoys during a period of 2 years. They attributed this overestimate to the mixing length scales used in the model for temperature and moisture. For the ARPEGE model, Eymard et al. [2003] found an overestimate of the latent heat loss during $\mathrm{FETCH}$, which they attributed to the exchange coefficients of the model bulk parameterization. Note that the PFE are in much better agreement with the buoy data than the NWP models in terms of estimating the latent heat flux.

\subsubsection{Sensible Heat Flux}

[60] The ECMWF model also overestimates the sensible heat loss by $9 \mathrm{~W} \mathrm{~m}^{-2}$ but the ARPEGE model does not, which results in a positive mean value for sensible heat corresponding to ocean warming (Table 10), like PFE.

\subsubsection{Radiative Heat Fluxes}

[61] For the radiative fluxes, the ARPEGE model overestimates the net longwave heat loss by $54 \%$, while the ECMWF model underestimates the net shortwave heat gain of $17 \%$ (Table 10), due to the simulated cloud cover. Josey [2001] also found an underestimate of the ECMWF model of the solar flux $(7 \%)$ together with an overestimate of the longwave flux, in particular for the two buoys of the Subduction Experiment closest to the POMME zone. Similarly, previous comparisons of radiative fluxes during SEMAPHORE [Eymard et al., 1996], CATCH [Weill et al., 2003], and FETCH [Eymard et al., 2003] confirm that strong biases may occur in the ECMWF and ARPEGE models. These biases are associated to recurrent, unresolved problems of cloud parameterization as noted by several authors.

\subsubsection{Net Heat Flux}

[62] The net heat flux loss of the two NWP models is much stronger than that of the buoy. The differences are important: $-63 \pm 3 \mathrm{~W} \mathrm{~m}^{-2}$ for ARPEGE and $-55 \pm$ $4 \mathrm{~W} \mathrm{~m}^{-2}$ for ECMWF (Table 10). These differences result mainly from the overestimate of latent heat loss by the two models. In the case of the ECMWF model, there is a contribution due to an underestimate of the shortwave flux, whereas for ARPEGE, there is a contribution from the longwave flux. Josey [2001] and Weller et al. [2004] found that the ECMWF bias is due to the contribution of latent heat and solar fluxes. Note that there is no compensation for bias in the ECMWF model since all the components of the net heat flux are underestimated except the longwave flux. However, this is only for the latent heat and for the longwave flux in the ARPEGE model. Note once more that the PFE provides the closest values to those of the buoy.

\subsubsection{Wind Stress}

[63] The stress measured by the buoy is overestimated, in descending order, by the ECMWF model (27\%), ARPEGE $(21 \%)$ and PFE (7\%) (Table 10).

\subsection{6. $E-P$}

[64] The differences for $E-P$ at the buoy location between ARPEGE, ECMWF and PFE mainly reflect the differences in evaporation (Table 10). Consequently, ARPEGE has the higher (positive) $E-P$ flux followed by the ECMWF model and finally PFE, for which precipitation dominates the $E-P$ budget and ultimately contributes to the freshening of the budget.

\subsection{Comparisons Along the Ship Trajectory (Period of Warming/Retreat)}

[65] The period during which the $\mathrm{R} / \mathrm{V}$ L'Atalante was at sea coincided with the beginning of the warming/retreat of the mixed layer (the "effective detrainment period" [Qiu and Huang, 1995]), an important period for subduction and completely different from the cooling/deepening period experienced earlier at the buoy site, making the two comparisons quite complementary. From Table 11 however, most of the conclusions of the previous paragraph can be confirmed: (1) the PFE overestimates the reference ship net 
Table 13. Comparison of the Annual Surface Flux Budget for Two NWP Models With the POMME Estimates and POMME Estimates Computed With Three Parameterization Schemes ${ }^{\mathrm{a}}$

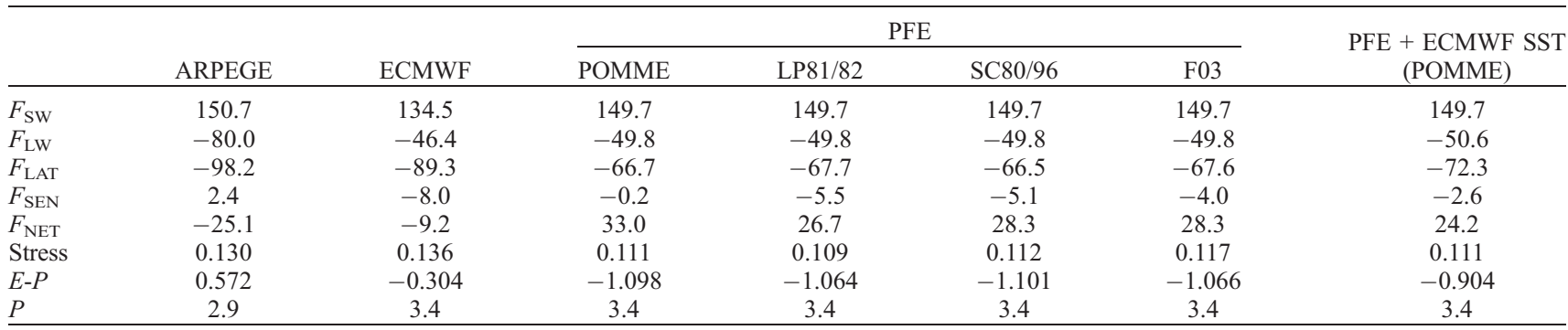

aparameterization schemes are as follows: LP81/82 [Large and Pond, 1981, 1982]; SC80/96 [Smith, 1980; DeCosmo et al., 1996 ]; and F03 [Fairall et al., 2003]. In the last column the budget was estimated with the POMME parameterization but by using the ECMWF SST analyses. Period considered was 2 September $2000-2001$. Domain was $21.33^{\circ}-15.33^{\circ} \mathrm{W}$ and $38^{\circ}-45^{\circ} \mathrm{N}$. Heat fluxes are in $\mathrm{W} \mathrm{m}^{-2}$; wind stress is in $\mathrm{N} \mathrm{m}^{-2}$; $E-P$ is in $\mathrm{mm} \mathrm{d}^{-1}$, and $P$ is in $\mathrm{mm}$.

heat flux by $22 \mathrm{~W} \mathrm{~m}^{-2}$ and the models underestimate the ship net heat flux: ARPEGE by $33 \mathrm{~W} \mathrm{~m}^{-2}$ and ECMWF by $12 \mathrm{~W} \mathrm{~m}^{-2}$; (2) for the ECMWF model the underestimated net heat flux comes mainly from underestimated shortwave flux; and (3) for ARPEGE, the underestimated net heat flux comes mainly from the longwave and the latent heat fluxes. However some differences emerge.

[66] 1. The ship model bias of the radiative net fluxes are nearly the same as those for the buoy model, but the bias on the latent and sensible heat fluxes changed. These were smaller when compared with the ship than with the buoy.

[67] 2. For the net heat flux, the errors with the ship data are reduced compared with the buoy but the order remains unchanged: ARPEGE mostly underestimates the net heat flux, then ECMWF, finally PFE which overestimates the net heat gain. This result suggests that the biases are not systematic in the models but may evolve during the year.

\subsection{Comparison of the 1 Year Budget Over the POMME Area}

[68] In order to be compared exactly over the same area, the NWP model fluxes were linearly interpolated onto the same $5 \mathrm{~km}$ grid as for the PFE. Table 13 shows the results of the PFE and NWP model fluxes averaged over the experimental area and during 1 year (2 September 2000-2001).

[69] The annual PFE net heat flux is positive (warming by $33 \mathrm{~W} \mathrm{~m}^{-2}$ ) and dominated by the excess of net solar heat warming over the dominant latent heat loss. The freshwater flux is negative $\left(-1.1 \mathrm{~mm} \mathrm{~d}^{-1}\right)$, meaning a freshening of the ocean. On the contrary, both NWP models have a negative heat budget (loss). Note the good agreement of the mean net solar heat flux between ARPEGE and PFE, but the large differences on both the latent heat and longwave fluxes, which cause the large difference in net heat fluxes compared to PFE (58 $\mathrm{W} \mathrm{m}^{-2}$ for ARPEGE) (Table 13).

[70] ECMWF overestimates the PFE latent heat loss but this loss does not exceed that of the ARPEGE model. Moreover, the ECMWF model underestimates the net solar radiation, the result being a large mean underestimate of the net heat flux compared to PFE $\left(42 \mathrm{~W} \mathrm{~m}^{-2}\right)$. Differences in the net heat flux are important between the three data sets, as they are approximately of the same order as the longwave heat flux.

[71] The freshwater budget indicates that in the PFE, precipitation exceeds evaporation (freshening), as is also found in ECMWF, but not in ARPEGE, corresponding to a saltening. Moreover, the precipitation rates used for PFE could not be evaluated against in situ data because we are not confident in the rate of precipitation measured onboard the ship [Prigent, 2003]; so that we cannot gain further confidence in the NWP models with regards to this estimate. Hence the freshwater budget is largely uncertain. Note finally that the PFE wind stress is weaker than that of both NWP models.

[72] Figure 5 is the $2 \mathrm{D}$ annual domain mean of the net heat flux and $E-P$ for ARPEGE, ECMWF and PFE. Figures $5 a-5 c$ indicate that the spatial patterns of the net heat flux are strongly different between PFE and also between each model. Substantial spatial variations are present in the PFE and none of its patterns are captured by the models. This is due to the model coarser resolution compared to the PFE radiation fields (shortwave and longwave) and the SST fields which influence both the net longwave and stability function for computing the sensible and latent heat fluxes. More surprisingly, the spatial structures differ largely between the various models. These differences originate primarily from the differences in the latent heat fields, their weight in the surface budget being important compared with the weight of the sensible heat, and its spatial variability being rather large.

[73] E-P budgets (Figures 5d-5f) also exhibit large differences; the plots present an overall north to south gradient. However, the ARPEGE model is positive almost everywhere except in the far north of the domain. The ECMWF model presents a negative budget north of $40^{\circ} \mathrm{N}$ and positive southward; and PFE is negative (freshening) everywhere. Note that quite similar patterns are obtained in ECMWF and PFE because of the precipitation fields being the same, despite very distinct patterns of evaporation: this means that in $E-P$, precipitation is the most important contribution for structuring this field.

[74] Wind stress fields (not shown) exhibit very similar patterns with a cyclonic tendency in the northern part of the domain and an anticyclonic tendency in the southern part.

[75] Sensitivity tests were performed to estimate the accuracy of the budget by varying the bulk algorithm used (Table 13). All the net heat budgets are positive (unlike those derived from the ECMWF and ARPEGE models) and differ in less than $7 \mathrm{~W} \mathrm{~m}^{-2}$, mainly due to variations of the sensible heat flux. Another sensitivity experiment was 

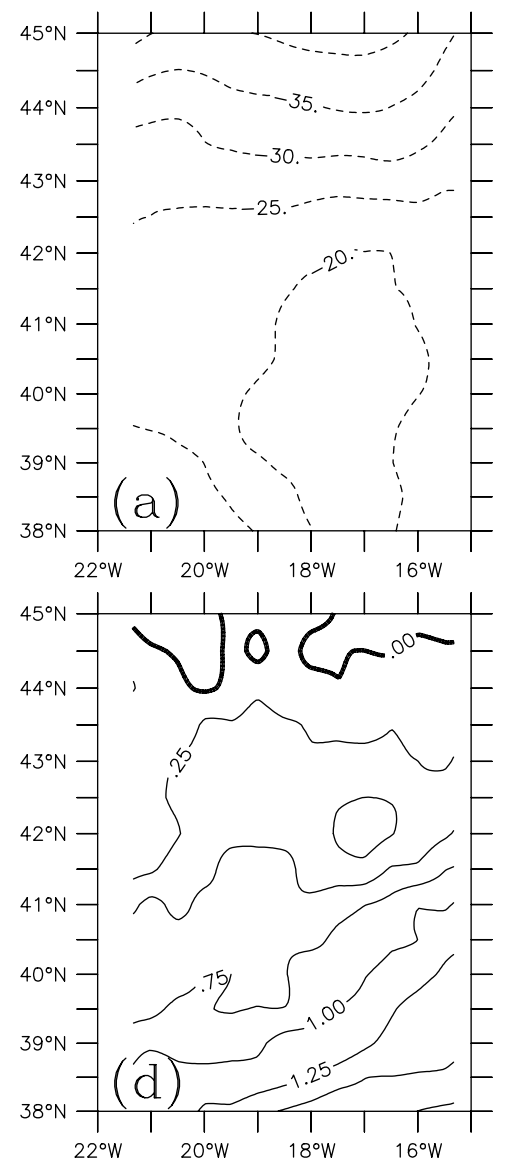
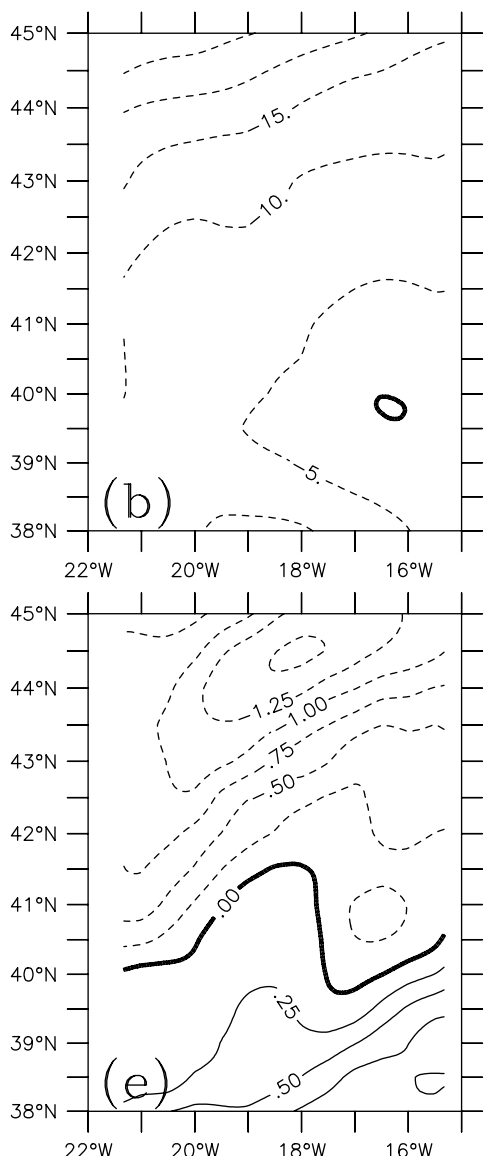
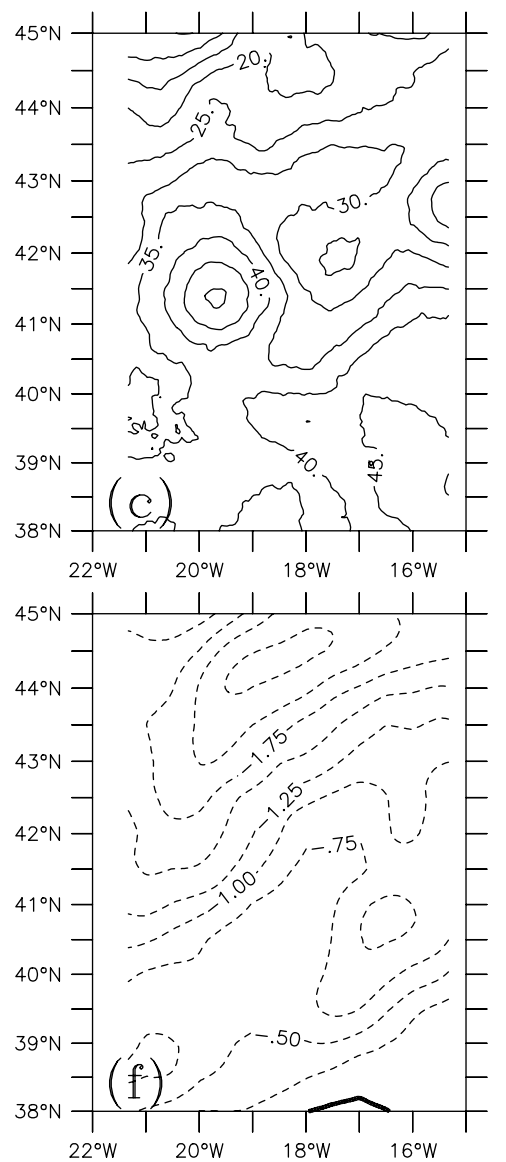

Figure 5. $(\mathrm{a}-\mathrm{c})$ Mean annual net heat flux in $\mathrm{W} \mathrm{m}^{-2}$ for ARPEGE, ECMWF, and PFE, respectively, with intervals of $5 \mathrm{~W} \mathrm{~m}^{-2}$ and dashed for negative values. $(\mathrm{d}-\mathrm{f})$ Mean annual freshwater budget in $\mathrm{mm} \mathrm{d}^{-1}$ for ARPEGE, ECMWF, and PFE, respectively, with intervals of $0.25 \mathrm{~mm} \mathrm{~d}^{-1}$ and dashed negative values.

performed by computing a new annual budget similar to PFE but by replacing the SST analyses with those of the ECMWF, so as to separate the effect of the model parameterization and the use of different SSTs. The budget is presented in the last column of Table 13. The largest differences with the PFE are due to the latent heat flux $\left(-5.6 \mathrm{~W} \mathrm{~m}^{-2}\right)$, the sensible heat flux $\left(-2.4 \mathrm{~W} \mathrm{~m}^{-2}\right)$ and the longwave $\left(-0.8 \mathrm{~W} \mathrm{~m}^{-2}\right)$. The net heat flux differs by $-8.8 \mathrm{~W} \mathrm{~m}^{-2}$. Moreover, mesoscale features present in Figure $5 \mathrm{c}$ are not reproduced with ECMWF SST analyses (not shown). This sensitivity test demonstrates the importance of the choice of SST analyses and of computing fluxes at a fine resolution for constructing fluxes at the mesoscale. Compared to the ECMWF budget, we infer that changing SST analyses represents about one fifth of the difference between the ECMWF model and the PFE mean net heat flux.

\section{Conclusions}

[76] A net heat and water budget has been estimated on an oceanic domain of $500 \times 750 \mathrm{~km}^{2}$ corresponding to the zone investigated during the POMME experiment. The method used consists in reconstructing each component of the budget by using the best available fields in the zone. Thus radiative fluxes are satellite fine-scale products and turbulent fluxes are computed with a state-of-the-art bulk algorithm. The last was specifically constrained during POMME with the turbulent data collected with the instrumented mast mounted on a research vessel.

[77] As inputs for the bulk algorithm, the atmospheric observables were issued from the ECMWF model. In order to use SST fields at a fine resolution, we produced specific SST analyses from satellite data as well as from the numerous in situ data collected in the experiment area. These analyses were produced every 3 days by using only morning data to avoid merging heterogeneous data with the diurnal cycle. The adopted resolution of $5 \mathrm{~km}$ results from the modeling purpose of describing mesoscale features. Three day analyses were then linearly interpolated every day.

[78] In order to control each stage of the data selection and the flux estimates, a validation has been carried out by comparing input data with in situ data. The in situ reference is (1) the data set collected by a moored buoy especially installed in the zone for the needs of the air-sea interaction POMME subprogram (8 months) and (2) the data set collected on the instrumented mast onboard the $\mathrm{R} / \mathrm{V}$ L'Atalante (3 months). The comparison of the observables with ECMWF model outputs indicate that mean biases are weak and correlations are quite satisfactory. In the same way, the comparison of satellite radiative fluxes with in situ 
data can be considered as excellent, with mean biases of less than $2 \mathrm{~W} \mathrm{~m}^{-2}$.

[79] Turbulent fluxes were then calculated every $5 \mathrm{~km}$ after the interpolation of the atmospheric observables. New comparisons with the net heat flux estimates at the moored buoy location and at the ship location indicate that the Pomme flux estimates are $13 \mathrm{~W} \mathrm{~m}^{-2}$ and $22 \mathrm{~W} \mathrm{~m}^{-2}$ greater than the observed estimates, respectively. This comparison, extended to the ECMWF and ARPEGE NWP models, indicates that the POMME flux estimates are closest to the moored buoy. This result consequently encourages us to believe that the synthesis approach is well adapted to estimate mesoscale flux fields.

[80] The comparison with NWP model fluxes conforms with previous results found in the literature: (1) an overestimate of latent heat cooling, the origin of which could be due to the model bulk flux parameterizations rather than due to errors on the input parameters and (2) the latent heat biases cumulate with biases on the radiative fluxes that increase the cooling component of the net heat flux; theses biases are largely associated with the parameterization of clouds in NWP models.

[81] In addition, a comparison of the annual (September 2000-2001) net heat flux from POMME, ECMWF and ARPEGE has been performed. The net heat flux is a gain of $33 \mathrm{~W} \mathrm{~m}^{-2}$ for the POMME fluxes with an excess of solar heating over the latent heat loss; the freshwater budget indicates a freshening of the ocean, with an excess of precipitation over evaporation. Large differences in spatial patterns were observed: the POMME flux fields shows a mesoscale signal which reflects the fine spatial resolution of SST, resulting in fine-scale structures on both latent and sensible heat flux fields. Owing to coarser model resolution, these structures were not present in the NWP models.

[82] Moreover, large differences of up to $58 \mathrm{~W} \mathrm{~m}^{-2}$ are obtained between the three mean annual budgets on the POMME area: for the POMME mesoscale fluxes the budget is positive $\left(33 \mathrm{~W} \mathrm{~m}^{-2}\right)$, while being negative in both the ECMWF $\left(-9 \mathrm{~W} \mathrm{~m}^{-2}\right)$ and ARPEGE $\left(-25 \mathrm{~W} \mathrm{~m}^{-2}\right)$ models. Sensitivity tests of the parameterization or to the SST analyses used places the accuracy of the budget to about $10 \mathrm{~W} \mathrm{~m}^{-2}$. These results suggest that the overestimated NWP heat loss derives from use of nonstandard bulk transfer coefficients. Furthermore, large differences are obtained in the freshwater budget with negative values for the POMME flux estimates $\left(-1.1 \mathrm{~mm} \mathrm{~d}^{-1}\right)$, meaning a mean annual freshening, whereas ARPEGE indicates a positive budget $\left(0.6 \mathrm{~mm} \mathrm{~d}^{-1}\right)$. The validity of these different products will be further assessed from the observed mixed layer thermal and salt content evolution. This work will be presented in a companion paper.

\section{Appendix A: SST Analyses}

[83] To obtain daily SST analyses, the data is processed according to the following steps at each passage of the satellite.

[84] 1. The pixelized data are fitted onto the $5 \mathrm{~km}$ grid covering the POMME area. For this operation, the closest points $10 \mathrm{~km}$ around a given grid point are averaged. In order to eliminate isolated points, which could be affected by the edges of clouds, a quality index is applied at each grid point. This index corresponds to the number of satellite data present in a radius of $10 \mathrm{~km}$ around the grid point considered. If this index is lower than a certain threshold (in our case 10), the point is rejected. After this test, only SST seen by the satellite through large clear sky areas are selected.

[85] 2. A second test, aimed at eliminating any remaining erroneous data is then applied. When a gridded temperature is too far off a decadal SST climatology [Faugère et al., 2001] value, the temperature is eliminated. The threshold chosen is $1.5^{\circ} \mathrm{C}$.

[86] 3. At this step, only the gridded SST fields corresponding to a morning satellite passage are kept in order to avoid mixing data affected by diurnal cycle.

[87] 4. SST fields are then averaged over 3 consecutive days. This 3 day period generally ensures that enough points are obtained to cover the POMME area, even in winter when the cloud cover can be important. Generally, more than $90 \%$ of the whole area was covered in 3 days. If some points have still no temperature value, an iterative procedure is then applied; an averaged SST is computed around the missing point if at least 6 (on a maximum of 8) adjacent points are present; the procedure is repeated until each point of the POMME domain is covered. Generally, the whole domain is covered after a maximum of four iterations.

[88] 5. These 3 day satellite SST fields are then used as a first guess for an optimal interpolation procedure in order to incorporate the in situ data. Only data between 0 hours and 10 hours were considered, so that they cannot be affected by too large a diurnal heating. Previously, data which deviated by more than a certain threshold from the satellite guess fields were rejected to eliminate erroneous data. The optimal interpolation procedure used [De Mey and Ménard, 1989] carries out an analysis of the difference between the in situ data and the first-guess data and uses an isotropic correlation radius of $30 \mathrm{~km}$.

[89] 6. A median time filter has then been used at each grid point so that a temporal consistency is obtained between successive analyses.

[90] 7. The 3 day analyzed SST fields are then linearly interpolated in order to get daily SST fields.

[91] Acknowledgments. The authors wish to thank A. Brisson, P. LeBorgne, A. Marsouin, and H. Roquet from the French Meteorological Centre de Météorologie Spatiale in Lannion (CMS) for providing the satellite data in near-real-time during all the POMME program. Special thanks to the team at the Centre de Météorologie Marine (CMM) in Brest for their help in the deployment of the OSAS buoy, to P. Durand, Y. Prigent, D. Legain, and T. Douffet, who installed extra radiative sensors on this buoy, to Y. Amar for his help in the treatment of all the data collected, and to A. Pirani for greatly improving the English of the manuscript. We also thank two anonymous reviewers and A. Oschlies for their useful comments. This work was supported by funding from "Institut National des Sciences de l'Univers" ("Programme Atmosphère Météorologique Océan Superficiel") and Meteo-France.

\section{References}

Arpe, K., and E. Roeckner (1999), Simulation of the hydrological cycle over Europe: Model validation and impacts of increasing greenhouse gases, Adv. Water Resour., 23, 119-1005.

Beljaars, A. C. M. (1994), The parameterization of surface fluxes in large-scale models under free convection, $Q$. J. R. Meteorol. Soc., $121,255-270$. 
Beranger, K., L. Siefridt, B. Barnier, E. Garnier, and H. Roquet (1999), Evaluation of operational ECMWF surface freshwater fluxes over oceans during 1991-1997, J. Mar. Syst., 22, 13-36.

Bignami, F., S. Marullo, R. Santoleri, and M. E. Schiano (1995), Longwave radiation budget in the Mediterranean Sea, J. Geophys. Res., 100, $2501-$ 2514

Bonekamp, H., G. J. Komen, A. Sterl, P. A. E. M. Janssen, P. K. Taylor, and M. J. Yelland (2002), Statistical comparisons of observed and ECMWF modeled open ocean surface drag, J. Phys. Oceanogr., 32, $1010-1027$

Bourras, D., W. T. Liu, L. Eymard, and T. Wenqing (2003), Evaluation of latent heat flux fields from satellites and models during SEMAPHORE, J. Appl. Meteorol., 42, 227-239.

Brisson, A., P. Le Borgne, A. Marsouin, and T. Moreau (1994), Surface irradiances calculated from METEOSAT sensor data during SOFIAASTEX, Int. J. Remote Sens., 15, 197-203.

Brisson, A., P. Le Borgne, and A. Marsouin (2002), Results of one year of pre-operational production of sea surface temperatures from GOES-8, J. Atmos. Oceanic Technol., 19, 1638-1652.

Brut, A. (2002), Mesures des échanges surface-atmosphère: Paramétrisation des flux sur l'océan pour la détermination de flux d'espèces en trace, Ph.D. thesis, 207 pp., Univ. Paul Sabatier, Toulouse, France.

Brut, A., A. Butet, P. Durand, G. Caniaux, and S. Planton (2005), Airsea exchanges in the equatorial area from the EQUALANT99 dataset: Bulk parameterizations of turbulent flux corrected for airflow distortion, Q. J. R. Meteorol. Soc., 131, 1-42.

Butet, A. (2002), Simulation du vent autour du N.O. ATALANTE, Note 24, Cent. Natl. de Recher. Meteorol., Toulouse, France.

Caniaux, G., and S. Planton (1998), A three-dimensional ocean mesoscale simulation using data from the SEMAPHORE experiment: Mixed layer heat budget, J. Geophys. Res., 103, 25,081-25,099.

Caniaux, G., S. Belamari, H. Giordani, A. Paci, L. Prieur, and G. Reverdin (2005), A 1 year sea surface heat budget in the northeastern Atlantic basin during the POMME experiment: 2. Flux optimization, J. Geophys. Res., 110, C07S03, doi:10.1029/2004JC002695.

Courtier, P., C. Freydier, J. F. Geleyn, F. Rabier, and M. Rochas (1991), The ARPEGE project at Météo-France, in ECMWF 1991 Seminar Proceedings: Numerical Methods in Atmospheric Models, ECMWF, 9-13 September 1991, vol. 2, pp. 123-231, Eur. Cent. for MediumRange Weather Forecasts, Reading U. K.

Curry, J. A., C. A. Clayson, W. B. Rossow, R. Reeder, Y. C. Zhang, P. J. Webster, G. Liu, and R. S. Sheu (1999), High-resolution satellite-derived dataset of the surface fluxes of heat, freshwater, and momentum for the TOGA COARE IOP, Bull. Am. Meteorol. Soc., 80, 2059-2080

Curry, J. A., et al. (2004), SEAFLUX, Bull. Am. Meteorol. Soc., 85, 409424, doi:10.1175/BAMS-85-3-409.

DeCosmo, J., K. B. Katsaros, S. D. Smith, R. J. Anderson, W. A. Oost, K. Bumke, and H. Chadwick (1996), Air-sea exchange of water vapor and sensible heat: The Humidity Exchange Over the Sea (HEXOS) results, J. Geophys. Res., 101, 12,001-12,016.

De Mey, P., and Y. Ménard (1989), Synoptic analysis and dynamical adjustment of GOES-3 and SEASAT altimeter eddy fields in the northwest Atlantic, J. Geophys. Res., 94, 6221-6230.

Dourado, M., and G. Caniaux (2001), Surface heat budget in oceanic simulation using data from Tropical Ocean-Global Atmosphere Coupled Ocean-Atmosphere Response Experiment, J. Geophys. Res., $106,16,623-16,640$

Dupuis, H., P. K. Taylor, A. Weill, and K. Katsaros (1997), Inertial dissipation method applied to derive turbulent fluxes over the ocean during the Surface of the Ocean, Fluxes and Interactions with the Atmosphere/ Atlantic Stratocumulus Transition Experiment (SOFIA/ASTEX) and Structure des Echanges Mer-Atmosphere, Proprietes des Heterogeneites Oceaniques: Recherche Experimentale (SEMAPHORE) experiments with low to moderate wind speeds, J. Geophys. Res., 102, 21,11521,129 .

Dupuis, H., C. Guérin, D. Hauser, A. Weill, P. Nacass, W. Drennan, S. Cloché, and H. Graber (2003), Impact of flow distortion corrections on turbulent fluxes estimated by the inertial dissipation method during the FETCH experiment on R/V L'Atalante, J. Geophys. Res., 108(C3), 8064, doi:10.1029/2001JC001075.

Eymard, L., et al. (1996), Study of the air-sea interactions at the mesoscale: The SEMAPHORE experiment, Ann. Geophys., 14, 986-1015.

Eymard, L., et al. (1999), Surface fluxes in the North Atlantic Current during the CATCH/FASTEX experiment, Q. J. R. Meteorol. Soc., 125 , 3563-3599.

Eymard, L., A. Weill, D. Bourras, C. Guérin, P. Le Borgne, and J. M. Lefèvre (2003), Use of ship mean data for validating model and satellite flux fields during the FETCH experiment, J. Geophys. Res., 108(C3), 8060, doi:10.1029/2001JC001207.
Fairall, C. W., E. F. Bradley, D. P. Rogers, J. B. Edson, and G. S. Young (1996), Bulk parameterization of air-sea fluxes for Tropical Ocean-Global Atmosphere Coupled-Ocean Atmosphere Response Experiment, J. Geophys. Res., 101, 3747-3764.

Fairall, C. W., A. B. White, J. B. Edson, and J. E. Hare (1997), Integrated shipboard measurements of the marine boundary layer, J. Atmos. Oceanic Technol., 14, 338-359.

Fairall, C. W., E. F. Bradley, J. E. Hare, A. A. Grachev, and J. B. Edson (2003), Bulk parameterization of air-sea fluxes: Updates and verification for the COARE algorithm, J. Clim., 16, 571-591.

Faugère, Y., P. Le Borgne, and H. Roquet (2001), Réalisation d'une climatologie mondiale de température de surface à échelle fine, La Meteorol., $35,24-35$.

Gao, X., S. Sorooshian, J. Li, and J. Xu (2003), SST data improve modeling of North American monsoon rainfall, Eos Trans. $A G U$, 84(43), 457, 462

Giordani, H., and G. Caniaux (2001), Sensitivity of cyclogenesis to sea surface temperature in the northwestern Atlantic, Mon. Weather Rev., $129,1273-1295$.

Giordani, H., S. Planton, B. Benech, and B.-H. Kwon (1998), Atmospheric boundary layer response to sea surface temperatures during the SEMAPHORE experiment, J. Geophys. Res., 103, 25,047-25,060.

Giordani, H., G. Caniaux, and L. Prieur (2005), A simplified 3D oceanic model assimilating geostrophic currents: Application to the POMME experiment, J. Phys. Oceanogr., 35, 628-644.

Gulev, S. K. (1997), Climatologically significant effects of space-time averaging in the North Atlantic sea-air heat flux fields, J. Clim., 10, $2743-2763$.

Isemer, H. J., and L. Hasse (1985), The Bunker Climate Atlas of the North Atlantic Ocean, vol. 1, Observations, 218 pp., Springer, New York.

Josey, S. A. (2001), A comparison of ECMWF, NCEP-NCAR, and SOC surface heat fluxes with moored buoy measurements in the subduction region of the northeast Atlantic, J. Clim., 14, 1780-1789.

Kent, E. C., P. K. Taylor, B. S. Truscott, and J. S. Hopkins (1993), The accuracy of voluntary observing ships meteorological observationsResults of the VSOP-NA, J. Atmos. Oceanic Technol., 10, 591-608.

Kubota, M., A. Kano, H. Muramatsu, and H. Tomita (2003), Intercomparison of various surface latent heat flux fields, J. Clim., 16, 670-678.

Large, W. G., and S. Pond (1981), Open ocean momentum flux measurement over the ocean, J. Phys. Oceanogr., 11, 324-336.

Large, W. G., and S. Pond (1982), Sensible and latent heat flux measurement over the ocean, J. Phys. Oceanogr., 12, 464-482.

Lévy, M., M. Gavart, L. Mémery, G. Caniaux, and A. Paci (2005), A fourdimensional mesoscale map of the spring bloom in the northeast Atlantic (POMME experiment): Results of a prognostic model, J. Geophys. Res., 110, C07S21, doi:10.1029/2004JC002588.

Lim, H. S., and C. H. Ho (2000), Comparison of tropical rainfall between the observed GPCP data and the assimilation products of ECMWF, NCEP/NCAR, and NASA-GEOS-1, J. Meteorol. Soc. Jpn., 78, 661672

Louis, J. F., M. Tiedtke, and J. F. Geleyn (1981), A short history of the operational PBL-parameterization at ECMWF, in ECMWF Workshop Proceedings on Planetary Boundary Layer Parameterization, pp. 5979, Eur. Cent. for Medium-Range Weather Forecasts, Reading, U. K.

Marshall, J. C., A. J. G. Nurser, and R. G. Williams (1993), Inferring the subduction rate and period over the North Atlantic, J. Phys. Oceanogr., 23, $1315-1329$

McGillis, W. R., J. B. Edson, J. E. Hare, and C. W. Fairall (2001), Direct covariance air-sea $\mathrm{CO}_{2}$ fluxes, J. Geophys. Res., 106, 16,729-16,745.

McLaren, A. J., and R. G. Williams (2001), Interannual variability in the thermodynamics of subduction over the North Atlantic, J. Phys. Oceanogr., 31, 3284-3294.

Mémery, L., G. Reverdin, J. Paillet, and A. Oschlies (2005), Introduction to the POMME special section: Thermocline ventilation and biogeochemical tracer distribution in the northeast Atlantic Ocean and impact of mesoscale dynamics, J. Geophys. Res., doi:10.1029/2005JC002976, in press.

Moyer, K. A., and R. A. Weller (1997), Observations of surface forcing from the Subduction Experiment: A comparison with global model products and climatological datasets, J. Clim., 10, 2725-2742.

Murray, F. W. (1967), On the computation of saturation vapor pressure, J. Appl. Meteorol., 6, 203-204.

Paci, A., G. Caniaux, M. Gavart, H. Giordani, M. Lévy, L. Prieur, and G. Reverdin (2005), A high-resolution simulation of the ocean during the POMME experiment: Simulation results and comparison with observations, J. Geophys. Res., doi:10.1029/2004JC002712, in press.

Paillet, J., and M. Arhan (1996), Oceanic ventilation in the eastern north Atlantic, J. Phys. Oceanogr., 26, 2036-2052.

Pedreros, R., G. Dardier, H. Dupuis, H. C. Graber, W. M. Drennan, A. Weill, C. Guérin, and P. Nacass (2003), Momentum and heat fluxes 
via the eddy correlation method on the R/V L'Atalante and an ASIS buoy, J. Geophys. Res., 108(C11), 3339, doi:10.1029/2002JC001449.

Prigent, Y. (2003), Campagne POMME, Février-Mai 2001: Documentation technique sur les mesures météorologiques, Note 26, 16 pp., Cent. Natl. de Recher. Meteorol., Toulouse, France.

Qiu, B., and R. X. Huang (1995), Ventilation of the North Atlantic and

North Pacific: Subduction versus obduction, J. Phys. Oceanogr., 25, 2374-2390

Rabier, F., J.-N. Thépaut, and P. Courtier (1998), Extended assimilation and forecast experiments with a four-dimensional variational assimilation system, Q. J. R. Meteorol. Soc., 124, 1861-1887.

Ramos-Buarque, S., H. Giordani, G. Caniaux, and S. Planton (2004), ERA-40 Ocean Surface Heat Fluxes: Evaluation of the model spins, Dyn. Atmos. Oceans, 37, 295-311.

Renfrew, I. A., G. W. K. Moore, S. Guest Peter, and K. Bumke (2002), A comparison of surface layer and surface turbulent flux observations over the Labrador Sea with ECMWF analyses and NCEP reanalyses, J. Phys. Oceanogr., 32, 383-400.

Reynolds, R. W., and T. M. Smith (1994), Improved global sea surface temperature analyses using optimum interpolation, J. Clim., 7, 929-948.

Schulz, J., P. Schluessel, and H. Grassl (1993), Water vapour in the atmospheric boundary layer over oceans from SSM/I measurements, Int. J. Remote Sens., 14, 2773-2789.

Sheu, R.-S., J. A. Curry, and G. Liu (1996), Satellite retrieval of tropical precipitation using combined International Satellite Cloud Climatology Project DX and SSM/I data, J. Geophys. Res., 101, 21,291-21,301.

Smith, S. D. (1980), Wind stress and heat flux over the ocean in gale force winds, J. Phys. Oceanogr., 10, 709-726.

Smith, S. D., et al. (1992), Sea surface wind stress and drag coefficients: The HEXOS results, Boundary Layer Meteorol., 60, 109-142.

Smith, S. R., D. M. Legler, and K. V. Verzone (2001), Quantifying uncertainties in NCEP reanalyses using high-quality research vessel observations, J. Clim., 14, 4062-4072.

Sun, B. R. A., Y. R. A. Lisan, and R. A. Weller (2003), Comparisons of surface meteorology and turbulent heat fluxes over the Atlantic: NWP model analyses versus moored buoy observations, J. Clim., 16, 679-695.
Trenberth, K. E. (1997), Using atmospheric budgets as a constraint on surface fluxes, J. Clim., 10, 2796-2809.

Weill, A., et al. (2003), Toward a better determination of turbulent air-sea fluxes from several experiments, J. Clim., 16, 600-618.

Weller, R. A., and S. P. Anderson (1996), Surface meteorology and air-sea fluxes in the western equatorial Pacific warm pool during the TOGA Coupled Ocean-Atmosphere Response Experiment, J. Clim., 9, 19591990 .

Weller, R. A., P. W. Furey, M. A. Spall, and R. E. Davis (2004), The largescale context for oceanic subduction in the northeast Atlantic, Deep Sea Res., Part I, 51, 665-699.

Woods, J. D., and W. Barkmann (1986), A Lagrangian mixed layer model of Atlantic $18^{\circ} \mathrm{C}$ water formation, Nature, 319, 574-576.

Yelland, M. J., and P. K. Taylor (1996), Wind stress measurements from the open ocean, J. Phys. Oceanogr., 26, 541-558.

Zeng, X. R. E., M. R. E. Zhao, and R. E. Dickinson (1998), Intercomparison of bulk aerodynamic algorithms for the computation of sea surface fluxes using TOGA COARE and TAO data, J. Clim., 11, $2628-2644$

D. Bourras, Centre d'Etude des Environnements Terrestre et Planétaires, 10-12, Avenue de 1'Europe, F-78140 Vélisy, France. (denis.bourras@ cetp.ipsl.fr)

A. Brut, G. Caniaux, H. Giordani, and A. Paci, Centre National de Recherches Météorologiques, 42 avenue G. Coriolis, F-31057 Toulouse Cedex, France. (brut@cnrm.meteo.fr; caniaux@meteo.fr; herve.giordani@ meteo.fr; alexandre.paci@meteo.fr)

L. Prieur, Laboratoire d'Océanographie de Villefranche-sur-mer, BP08, F-06230 Villefranche-sur-mer, France. (prieur@obs-vlfr.fr)

G. Reverdin, Laboratoire d'Océanographie et du Climat: Expérimentation et Approche Numérique, Institut Pierre Simon Laplace, 4, place Jussieu, F-75252 Paris Cedex 05, France. (reverdin@lodyc.jussieu.fr) 